Review Paper

\title{
Nanoparticles used as an ingredient in different types of concrete
}

\author{
Rawa Ahmed Mahmood ${ }^{1}$ [ $\cdot$ Niyazi Ugur Kockal ${ }^{1}$
}

Received: 3 November 2020 / Accepted: 2 March 2021 / Published online: 6 April 2021

(c) The Author(s) $2021 \quad$ OPEN

\begin{abstract}
Attempts to modify cement-based mixtures and to improve their properties have always attracted the attention of researchers. Favorable effects of nanoparticles, such as small particle size, high reactivity, and great surface area, have made them be used as one of the best replacements of cement. This paper aims to review the previous researches conducted regarding the effects of nanoparticles on the properties of concretes. Influence of various types of nanoparticles on the workability of fresh composite, mechanical properties such as compressive strength, flexural strength, splitting tensile strength, modulus of elasticity, and abrasion resistance, and durability-related properties such as water absorption, chloride ion penetration, resistance to frost, shrinkage, and carbonation of concrete is discussed.
\end{abstract}

Keywords Nanoparticle $\cdot$ Concrete $\cdot$ Workability $\cdot$ Mechanical properties $\cdot$ Durability-related properties

$\begin{array}{ll}\text { Abbreviations } \\ \text { ANP } & \text { Aluminum nanoparticle } \\ \text { ENM } & \text { Engineered nanomaterial } \\ \text { ENP } & \text { Engineered nanoparticles } \\ \text { FA } & \text { Fly ash } \\ \text { HPSCC } & \text { High-performance self-compacting concrete } \\ \text { HSC } & \text { High-strength concrete } \\ \text { HVF } & \text { High-volume fly ash } \\ \text { NC } & \text { Nano-CaCo } \\ \text { NS } & \text { Silica nanoparticle } \\ \text { NSC } & \text { Nano-silicon carbide } \\ \text { NT } & \text { Tio }_{2} \text { nanoparticle } \\ \text { RCPT } & \text { Rapid chloride penetration test } \\ \text { SCC } & \text { Self-compacting concrete } \\ \text { SF } & \text { Silica fume } \\ \text { UHPC } & \text { Ultra-high-performance concrete } \\ \text { UHPCC } & \text { Ultra-high-performance cementitious } \\ & \text { composite } \\ \text { UHSC } & \text { Ultra-high-strength concrete } \\ \text { W/B } & \text { Water-binder ratio } \\ \text { W/C } & \text { Water-cement ratio }\end{array}$

\section{Introduction}

Concrete is one of the most used construction materials worldwide. The production process of cement which is one of the main components of concrete involves a high amount of $\mathrm{CO}_{2}$ emissions which are about two billion tons/ year (nearly $7 \%$ of the planet's total $\mathrm{CO}_{2}$ emissions) [1]. It is expected that production of cement to reach about six billion tons/year by 2050 [2]. For the sake of minimizing the hazardous effects of cement on the environment and climate change, serious actions have been taken. A wide range of studies have been conducted regarding finding alternatives for cement such as the incorporation of pozzolans and nanoparticles. Nanoparticles can be better described as admixtures of concrete, which are newly used. Nanoparticles, in general, are used in cement-based materials not only as additives but also as cement replacement to improve some mechanical and durability-related properties due to their high reactivity and great surface area [3]. Nanotechnology is one of the newest and developing technologies. Drexler [4] defines nanotechnology as "the control of matter based on molecule-by-molecule control of products and by-products through high-precision

Rawa Ahmed Mahmood, rawa.ahmed12@gmail.com | 'Department of Civil Engineering, Akdeniz University, Antalya, Turkey. 
systems as well as the products and processes of molecular manufacturing, including molecular machinery." Nanoparticles have particles size ranging between 1 and $100 \mathrm{~nm}$ (Fig. 1). The utilization of nanoscaled materials in cementitious composites started at the beginning of the 1960s by Stein and Stevels who used nano-SiO ${ }_{2}$ in the alite paste [5]. There are many different fields of application of nanoparticles such as national defense, electronic engineering, chemical industry, aerospace engineering, biology engineering, and medical science due to their preferable physical and chemical properties [6]. Small particle sizes of nanoparticles help improve the microstructure of concrete by filling the pores in the cement paste and consequently increasing the packing level $[7,8]$. Nanoparticles also develop the strength of cement-based materials by improving the hydration process of cement and hence producing calcium-silica-hydrate (C-S-H) $[9,10]$. In civil engineering society researches have been undertaken and tests have been conducted on the use of nanoparticles such as nano-SiO2 $[6,9,11-17]$, nano- $\mathrm{CaCO}_{3}[18-20]$, nano- $\mathrm{TiO}_{2}[9,14,16,21,22]$, and nano- $\mathrm{Al}_{2} \mathrm{O}_{3}[14,23]$.

This paper provides an overview of the effects of nanoparticles on different types of concretes by studying the material properties of nanoparticles. Fresh-state properties; mechanical properties such as compressive strength, splitting tensile strength, flexural strength, abrasion resistance, and modulus of elasticity; and durability-related properties such as water absorption, chloride ion penetration, freezing and thawing resistance, shrinkage, and carbonation of mixtures include nanoparticles by reviewing existing studies in this area.

\section{Types and properties of nanomaterials used in cementitious mixtures}

Nanomaterials are used as cement replacement in various percentages. Tables 1, 2 list the type and properties of nanomaterial particles as reported in the literature. Listed in the tables are types of composites, nanomaterial type, and type of use. Among material properties, physical properties, including workability and air content, and mechanical properties, including compressive strength, flexural strength, splitting tensile strength, and modulus of elasticity of different types of concretes containing nanoparticles, are listed in tables below.

Specific Surface Area, $\mathrm{m}^{2} / \mathrm{kg}$

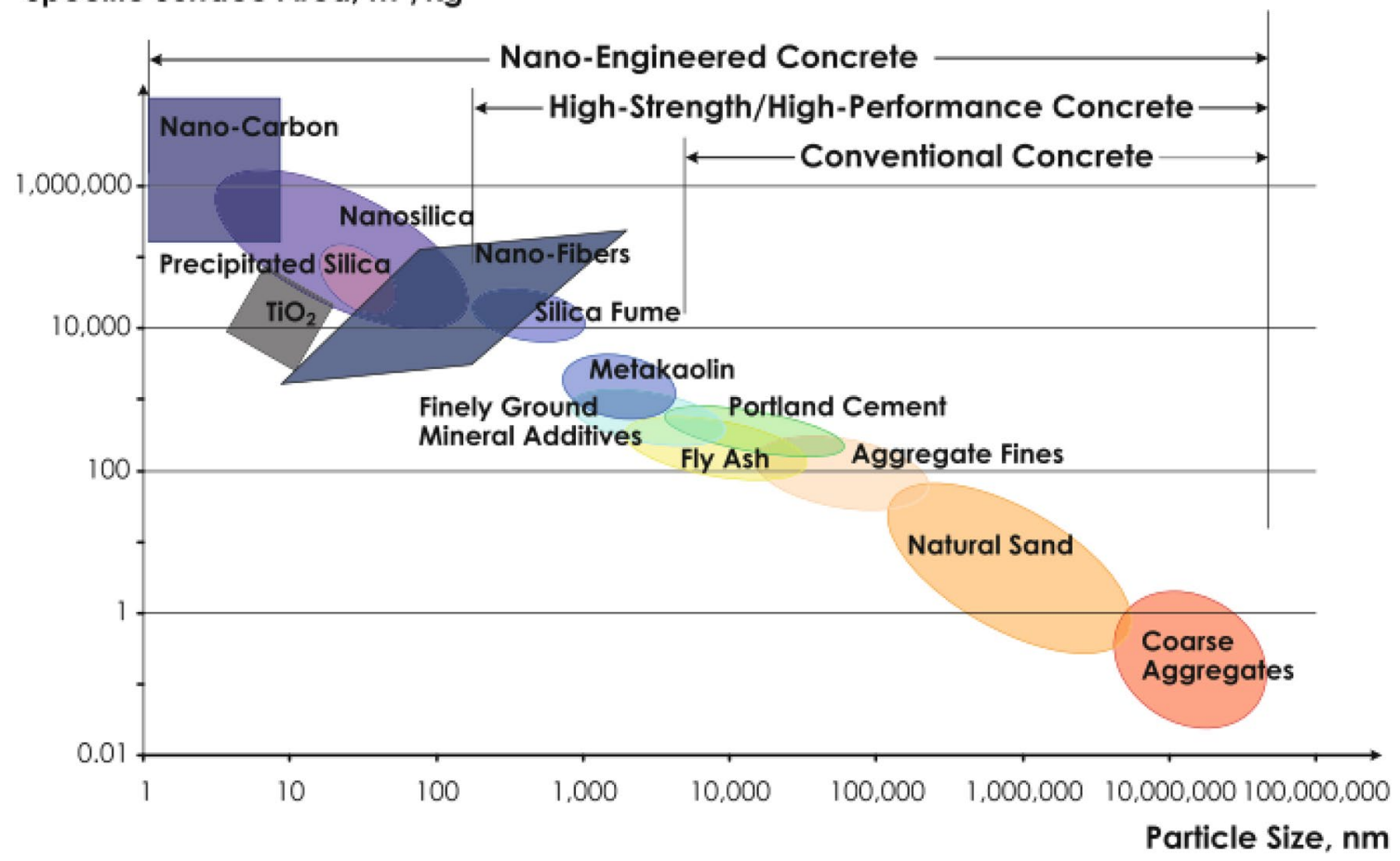

Fig.1 The particle size and specific surface area scale related to concrete materials [24] 


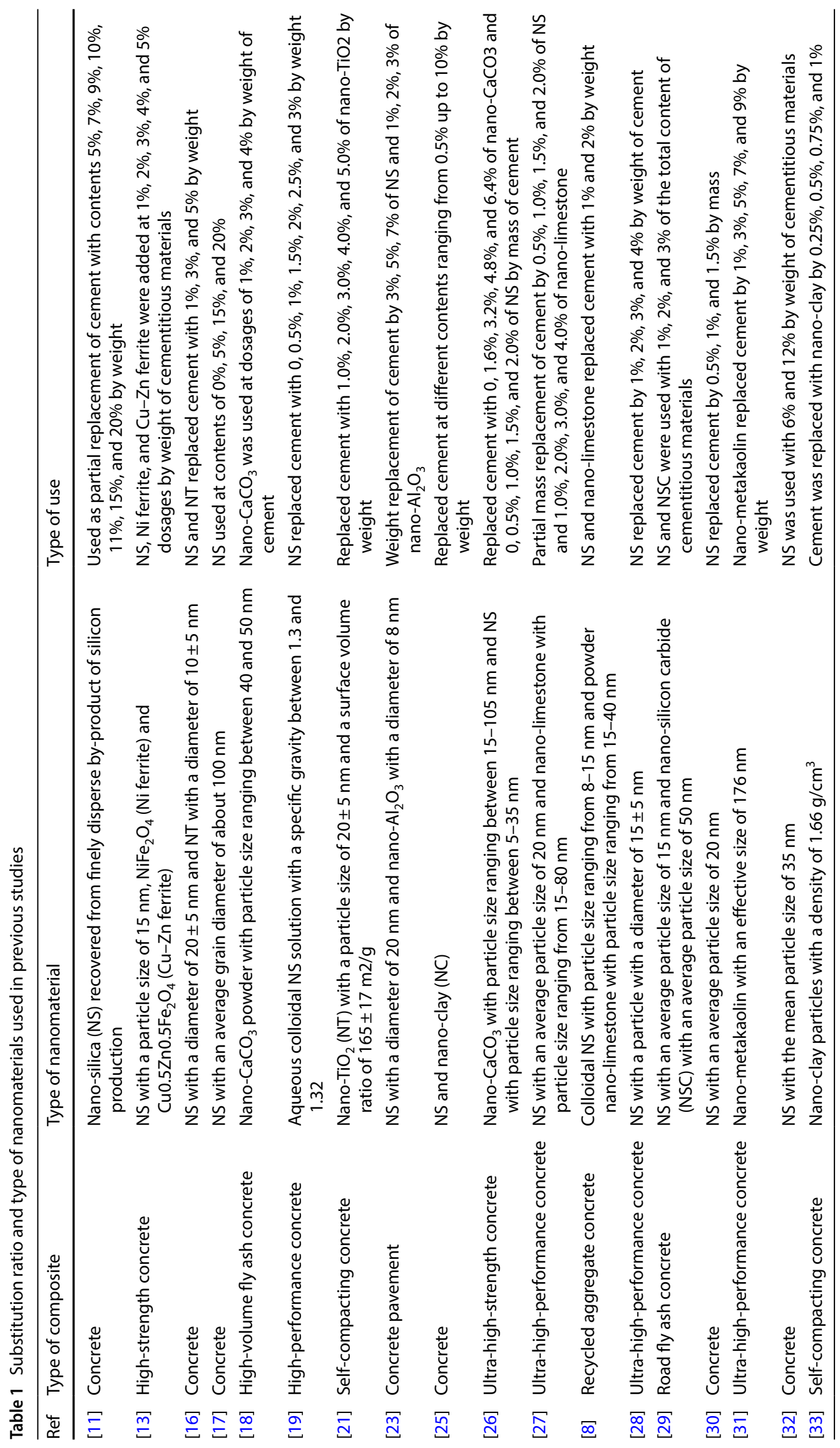


Table 2 Properties of nanomaterials used in previous studies

\begin{tabular}{|c|c|c|c|c|c|c|c|}
\hline \multirow[t]{2}{*}{ Ref } & \multirow[t]{2}{*}{ Type of nanomaterial } & \multicolumn{2}{|c|}{ Physical properties } & \multirow{2}{*}{$\begin{array}{l}\text { Hardened } \\
\text { Mechanical } \\
\text { Properties } \\
\text { Compressive } \\
\text { strength }\end{array}$} & \multirow[b]{2}{*}{$\begin{array}{l}\text { Splitting tensile } \\
\text { strength }\end{array}$} & \multirow[b]{2}{*}{$\begin{array}{l}\text { Flexural } \\
\text { strength }\end{array}$} & \multirow[b]{2}{*}{$\begin{array}{l}\text { Modulus } \\
\text { of elastic- } \\
\text { ity }\end{array}$} \\
\hline & & Workability & Density & & & & \\
\hline [11] & Nano-SiO2 & $\checkmark$ & $x$ & $\checkmark$ & $x$ & $x$ & $x$ \\
\hline [13] & Nano-SiO2 and nano-ferrite & $x$ & $x$ & $\checkmark$ & $\checkmark$ & $\checkmark$ & $\checkmark$ \\
\hline [16] & Nano-SiO2 and Nano-TiO2 & $\checkmark$ & $x$ & $\checkmark$ & $x$ & $\checkmark$ & $x$ \\
\hline [18] & Nano-CaCO3 & $\checkmark$ & $x$ & $\checkmark$ & $x$ & $\mathrm{x}$ & $x$ \\
\hline$[19]$ & Nano-SiO2 & $\checkmark$ & $x$ & $\checkmark$ & $\checkmark$ & $\checkmark$ & $x$ \\
\hline$[20]$ & Nano-SiO2 & $\checkmark$ & $x$ & $\checkmark$ & $\checkmark$ & $x$ & $x$ \\
\hline$[21]$ & Nano-TiO2 & $\checkmark$ & $x$ & $\checkmark$ & $\checkmark$ & $x$ & $x$ \\
\hline$[23]$ & Nano- $\mathrm{SiO}_{2}$ and Nano- $\mathrm{Al}_{2} \mathrm{O}_{3}$ & $\checkmark$ & $x$ & $\checkmark$ & $x$ & $x$ & $x$ \\
\hline$[25]$ & Nano-SiO2 and Nano-clay & $x$ & $x$ & $\checkmark$ & $\mathrm{x}$ & $\checkmark$ & $x$ \\
\hline$[26]$ & Nano-SiO2 and Nano-CaCO3 & $\checkmark$ & $x$ & $\checkmark$ & $x$ & $\checkmark$ & $x$ \\
\hline$[27]$ & Nano-SiO2 and Nano-CaCO3 & $x$ & $x$ & $\checkmark$ & $x$ & $\checkmark$ & $x$ \\
\hline$[8]$ & Nano-SiO2 and nano-limestone & $x$ & $x$ & $\checkmark$ & $x$ & $x$ & $x$ \\
\hline$[28]$ & Nano- $\mathrm{SiO}_{2}$ & $\checkmark$ & $x$ & $\checkmark$ & $x$ & $\mathrm{x}$ & $x$ \\
\hline$[30]$ & Nano- $\mathrm{SiO}_{2}$ & $\checkmark$ & $x$ & $\checkmark$ & $\mathrm{x}$ & $\mathrm{x}$ & $x$ \\
\hline$[31]$ & Nano-metakaolin & $\checkmark$ & $x$ & $\checkmark$ & $x$ & $\mathrm{x}$ & $x$ \\
\hline$[32]$ & Nano-SiO2 & $\mathrm{x}$ & $x$ & $\checkmark$ & $\checkmark$ & $x$ & $x$ \\
\hline [33] & Nano-clay & $\checkmark$ & $x$ & $\checkmark$ & $\checkmark$ & $x$ & $x$ \\
\hline [34] & Nano-SiO2 & $x$ & $x$ & $\checkmark$ & $x$ & $x$ & $x$ \\
\hline [35] & Nano-SiO2 & $x$ & $x$ & $\checkmark$ & $\checkmark$ & $\checkmark$ & $x$ \\
\hline [36] & Nano-clay & $\checkmark$ & $x$ & $\checkmark$ & $\checkmark$ & $x$ & $\checkmark$ \\
\hline [37] & $\mathrm{Nano}_{-} \mathrm{SiO}_{2}$ & $\checkmark$ & $\checkmark$ & $\checkmark$ & $\checkmark$ & $x$ & $x$ \\
\hline
\end{tabular}

\section{Effects of nanoparticles on the properties of various types of concrete}

\subsection{Self-compacting concrete (SCC)}

In a study conducted by Jalal et al. [38], various properties of high-performance self-compacting concrete (HPSCC) containing silica fume (SF), silica nanoparticles (NS), and class F fly ash (FA) were investigated. NS, SF, and SF + NS replaced Portland cement with a percentage of $2 \%, 10 \%$, and $10 \%+2 \%$, respectively, with the water/binder ratio being kept constant of 0.38 . Rheological properties of HPSCC were measured by V-funnel (s) and slump flow $(\mathrm{mm})$. Results showed that the addition of $2 \%$ NS did not have any significant effect on the workability, while the addition of FA increased workability at different percentages. V-funnel test results showed the lowest flow time for $10 \%$ and $15 \%$ addition of FA which was $2.5 \mathrm{~s}$ and the highest for $2 \%$ addition of NS which was $12 \mathrm{~s}$.

Joshaghani et al. [39] showed that the slump flow diameter of SCC containing various types of nanoparticles exhibits a decreasing trend due to the small particle size of nanomaterials and their tendency to consume a higher amount of water. However, the addition of nanoparticles up to $3 \%$ improved the V-funnel and L-box behavior of SCC samples. For the higher amounts of nanoparticles, the workability of SCC decreased due to the formation of a viscous mixture.

Flexural strength of HPSCC for $10 \%$ SF and $2 \%$ NS at binder amounts of 400 and $500 \mathrm{~kg} / \mathrm{m}^{3}$, increased by $23.5 \%$, $58.9 \%, 47 \%$ and $20 \%, 52 \%, 52 \%$ at 7,28 , and 90 days, respectively [38]. This increase in the flexural strength has been explained by some researchers who have conducted studies on silica nanoparticles as following:

(a). The incorporation of nanoparticles plays a good role in filling the cement pores, which leads to an increase in strength [38].

(b). Uniform dispersion of small content of silica nanoparticles in the cement paste has led the nanoparticles to connect with cement hydrate strongly, and the high activity of nanoparticles improves the hydration process which then results in strength increment of the cement mortar [28].

(c). Restriction of the development of crystals by the nanoparticles that play an affirmative role in the strength of the matrix. [40, 41]. 
Langaroudi and Mohammedi [36] reported that the addition of NC by weight of cement increased the modulus of elasticity of SCC. Jalal et al. [21] found that the addition of $\mathrm{TiO}_{2}$ nanoparticles up to $4 \%$ by weight increases splitting tensile strength and then strength decreases with further additions (Fig. 8). The authors reported that the replacement of $\mathrm{TiO}_{2}$ nanoparticles up to $4 \%$ speeds up the formation of $\mathrm{C}-\mathrm{S}-\mathrm{H}$ gel which leads to enhance splitting tensile strength as a result of increased crystalline $\mathrm{Ca}(\mathrm{OH})_{2}$ at the early age of hydration. The findings of Niewiadomski et al. [42] show favorable effects of different types of nanoparticles such as $\mathrm{SiO}_{2}, \mathrm{TiO}_{2}$, and $\mathrm{Al}_{2} \mathrm{O}_{3}$ on the improvement of mechanical properties of SCC. The compressive strength of SCC was enhanced upon the addition of nanoparticles. In the case of flexural strength, the concrete samples containing $0.5 \%$ of nano- $\mathrm{SiO}_{2}$ and nano- $\mathrm{TiO}_{2}$ had higher strength values than the reference sample. The authors also stated that all SCC samples produced with the addition of nanoparticles had lower values of flexural strength at 90 days; however, they did not explain the reasons behind having lower strength.

The study conducted by Dolatabad et al. [14] on the effects of different types of nanomaterials such as nano$\mathrm{SiO}_{2}$, nano- $\mathrm{TiO}_{2}$, and nano- $\mathrm{Al}_{2} \mathrm{O}_{3}$ revealed the enhanced acid resistance and water permeability of lightweight SCC. An incline in the water permeability values was observed upon the addition of nanoparticles. The authors reported a reduction by $15 \%$ and $18 \%$ in the water penetration depth of the SCC sample with $2 \%$ by weight of NS at the curing ages of 28 and 56 days, respectively. Increasing the amount of nanoparticles led to the formation of a less permeable structure. The addition of nanoparticles improved the resistance of the mixture against the acidic medium since all SCC samples produced with nanoparticles had less weight loss compared to the reference sample after 70 days of immersion in an acidic medium of $5 \% \mathrm{H}_{2} \mathrm{SO}_{4}$ solution (Fig. 2). When Fig. 2 is observed, it can be seen that SCC samples containing $4 \%$ of nano- $\mathrm{TiO}_{2}$ have the lowest rate of weight loss.

In the study conducted by Jalal et al. [21], it was seen that chloride permeability decreased as the amount of $\mathrm{TiO}_{2}$ nanoparticles increased up to an optimal level which was $4 \%$ in this study. Beyond $4 \%$, chloride permeability slightly increased due to the weaker pore structure of concrete at high amounts of $\mathrm{TiO}_{2}$ nanoparticles. The authors explained this weak pore structure and stated that it could be attributed to the space between nanoparticles which gets narrower as the amount of nanoparticles increases; this causes a decrease in the crystal quantity since there is not enough space for $\mathrm{Ca}(\mathrm{OH})_{2}$ crystals to grow up; this results in shrinkage and increase in creep of the cement matrix; and thus, weak pore structure of cement matrix leads to an increase in the chloride penetration. In a study

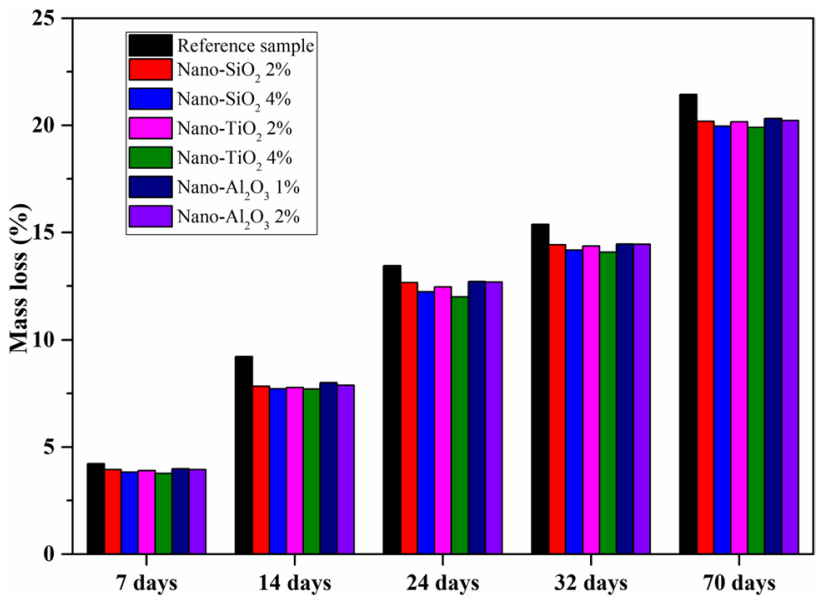

Fig. 2 Weight loss (\%) versus time for SCC samples exposed to $5 \%$ of $\mathrm{H}_{2} \mathrm{SO}_{4}$ solutions [14]

done by Quercia et al. [37], it was concluded that incorporation of NS together with air introduced agent to concrete highly developed resistance against freezing and thawing. The authors attributed this development to the formation of C-S-H gel and refined pore structure that blocked water penetration to concrete, so concrete became resistant to various temperatures close to the concrete surface.

Observations above indicate that the incorporation of nanoparticles can imply a favorable effect on the properties of SCC. Enhanced properties can be attributed to the particle size effect of the nanoparticles which leads to the formation of a denser structure through filling pores in the cement matrix. This is an essential point when considering the permeability of concrete since the addition of nanoparticles reduces the numbers of capillary pores which results in the prevention of water and chemical substances that harm the concrete. Consequently improved mechanical and durability-related properties can be obtained. However, the incorporation of nanoparticles is seen to negatively affect the workability performance of SCC, due to the formation of a viscous structure owing to the finer size of nanoparticles. The amount of nanoparticles may vary from one study to another; hence, different results can be achieved. Optimizations on the amounts of nanoparticles can provide a better overview of the optimum content of the nanoparticles to be used to improve the performance of SCC.

\subsection{High-performance concrete (HPC)}

Observations by Chitrha et al. [19] showed that utilization of NS leads to the reduction in the workability of high-performance slag concrete HPSC due to the high surface area and reactivity of NS particles which causes the absorption of mixing water by nanoparticles and 
consequently reduces the amount of free water needed to enhance workability. To overcome the water demand, the authors suggest that a superplasticizer should be used. The authors also reported that with $0.4 \%$ of superplasticizer the slump value was $32 \mathrm{~mm}$ for $1 \%$ of NS; however, when the amount of superplasticizer increased to $0.6 \%$, the slump increased slightly and got the value of $47 \mathrm{~mm}$ for $3 \%$ of NS (Fig. 5).

Using NS as a partial replacement of cement increased the flexural strength of HPC [19]. The flexural strength in all replacement ratios was greater than the control concrete; hence, the best results were obtained with the $2 \%$ incorporation of NS which were $41 \%, 37.7 \%, 36.5 \%$, and $32 \%$ greater than the reference specimen for $3,7,28$, and 90 days of curing, respectively [19]. Khaloo et al. [34] studied the effects of different types of NS with different surface areas such as 200 and $380 \mathrm{~m}^{2} / \mathrm{g}$ at different $\mathrm{w} / \mathrm{b}$ ratios on the properties of HPC. It is reported that at a $0.25 \mathrm{w} / \mathrm{b}$ ratio, the reference concrete at 28 and 91 days of curing had a higher splitting tensile strength than the specimen containing NS380. This phenomenon was attributed to the higher surface area of NS, which increased the probability of nanoparticles to agglomerate. Furthermore, the specimen produced with NS200 had a higher splitting tensile strength value than both NS380 and the reference sample. This situation can be explained by the lower possibility of the formation of the agglomerates with lower specific surface areas of NS200. The authors concluded that in general NS with a lower specific surface area (NS200) is more effective in improving the splitting tensile strength of HPC than NS380.

Observations reported by Chithra et al. [19] revealed a decrease in the water absorption values for concrete specimens containing NS. The water absorption was measured to be $2.99 \%, 1.95 \%$, and $2.17 \%$ for $0 \%, 2 \%$, and $3 \%$ replacement of NS by weight, respectively, at 28 days of curing. The authors explained this reduction in water absorption by the pozzolanic effects of NS, which produced a denser and more compacted concrete. Also, the pore-filling property of the very fine NS particles helps to improve the pore structure of the concrete, which then leads to lower water absorption of concrete. Resistance against chloride penetration increased with the addition of NS up to $2 \%$. It was also concluded that more coulomb charges passed at 28 days than 90 days. The decrease in the penetration of chloride ions was explained by the denser microstructure and refined pore structure.

Jalal et al. [38] reported that $2 \%$ addition of NS to concrete decreased water absorption by $35 \%$ and $32 \%$ for binder amounts of 400 and $500 \mathrm{~kg} / \mathrm{m}^{3}$, respectively, which showed better water impermeability of concrete with the addition of NS when compared to traditional concrete. The authors also reported a $58 \%$ and $54 \%$ reduction in capillary water absorption with a $2 \%$ addition of NS for binder content of 400 and $500 \mathrm{~kg} / \mathrm{m}^{3}$, respectively. Furthermore, a $2 \%$ addition of NS decreased the chloride ion permeability by $43 \%$ for both binder contents of 400 and $500 \mathrm{~kg} / \mathrm{m}^{3}$ in samples having a depth of $0-5 \mathrm{~mm}$.

Nanoparticles with different surface areas have different effects on the concrete. Nanoparticles with a high specific surface area are more likely to agglomerate which reduces their favorable effects, whereas those with the lower surface area have a low tendency to form agglomerates and improve properties of HPC. The amount of nanoparticles can be considered as an important factor in the performance of the concrete. Studies have shown that up to $2 \%$ addition of NS, the strength of HPC reached the maximum value; however, at higher amounts of NS the pozzolanic action was reduced. It can be due to the existence of more nano-silica than the liberated lime. Further focuses on these parameters can construct a better understanding of the use of nanoparticles, and hence, more benefits of them can be obtained.

\subsection{Ultra-high-performance concrete (UHPC)}

Norhasri et al. [31] reported a gradual decrease in the workability of UHPC upon the addition of metakaolin nanoparticles. Slump values were reduced by $15.73 \%$ with the $9 \%$ replacement of cement by nano-metakaolin (Fig. 5). The greater surface area of the UHPC mix due to the incorporation of nano-metakaolin was assigned as the reason behind the reduction in the workability. The smaller particle size of metakaolin nanoparticles increased the surface area and hence more surface area needed to be covered which consequently led to the reduction of workability of UHPC.

Rong et al. [20] investigated the effects of NS on the properties of ultra-high-performance cementitious composites (UHPCC). They concluded that with up to $3 \%$ content of NS the flexural strength increased but then decreased at higher amounts of NS. This reduction was attributed to the accumulation of NS particles at higher contents. Li et al. [27] also evaluated the effects of nano$\mathrm{SiO}_{2}$ and nano- $\mathrm{CaCO}_{3}$ on the properties of ultra-highperformance concrete (UHPC). The results supported the studies of Wu et al. [26]. Flexural strength increased up to an optimal amount of NS incorporation, which was $1 \%$ in this study, and then decreased at higher contents but still greater than the reference specimen (Fig. 7). Flexural strength increased by $41 \%$ and $35 \%$ for the replacement amount of $1 \%$ for the $w / b$ ratio of 0.16 and 0.17 , respectively. When the replacement amount of NS increased to $2 \%$, the flexural strength was measured to be $31 \%$ and $18 \%$ higher than the control specimen for a $\mathrm{w} / \mathrm{b}$ ratio of 0.16 and 0.17 , respectively. Like NS, the incorporation of 
NC also increased flexural strength. $3 \%$ replacement of NC improved the flexural strength of UHPC by about $40 \%$ and $30 \%$ for a $\mathrm{w} / \mathrm{b}$ ratio of 0.16 and 0.17 . This increment was explained by the nucleation effect induced by NC [43]. An investigation conducted by Norhasri et al. [31] showed that the metakaolin nanoparticles have no significant effect on the early age strength enhancement of UHPC. The authors explained this situation by the retardation of the filling process of nano-metakaolin particles due to the packed constituents in the UHPC mix. Furthermore, at higher amounts of nano-metakaolin, the incomplete filling process caused the formation of unhydrated products which then weakened the bond between the aggregates and cement paste.

Calvo et al. [44] developed UHPC with the incorporation of an innovative self-healing system based on two micro/ nano-additions which were silica microcapsules containing epoxy sealing compound and amine-functionalized NS particles. The utilization of this self-healing system was considered to enhance the durability of UHPC since it causes a reduction in the values of the initial suction capillary coefficient. Furthermore, it is reported that the cracked control mixture had greater water absorption than cracked self-healing UHPC samples.

In general, the addition of nanoparticles causes a reduction in the workability of UHPC. Reported results in the literature show that as the particle size gets smaller, their surface area increases, and hence more amount of water is required for proper workability. The strength of concrete is affected by the $\mathrm{w} / \mathrm{b}$ ratio. Studies show that with a low $\mathrm{w} / \mathrm{b}$ ratio, higher strength performance of UHPC can be achieved.

\subsection{High-strength concrete (HSC)}

Amin and el-hassan [13] investigated the effects of different nanomaterials such as NS and nano-ferrite (NiFe2O4 [Ni ferrite] and $\mathrm{Cu} 0.5 \mathrm{Zn} 0.5 \mathrm{Fe} 2 \mathrm{O} 4$ [Cu-Zn ferrite]) on the properties of HSC. Improved behavior of the splitting tensile strength with the addition of nanoparticles was observed. The splitting tensile strength was developed by $44 \%, 60 \%$, and $60 \%$ for addition of content of $15 \%$ of NS, $10 \%$ of $\mathrm{Ni}$ ferrite, and $10 \%$ of $\mathrm{Cu}-\mathrm{Zn}$ ferrite, respectively, with respect to the reference sample (Fig. 8). The optimum amount of nanoparticles to be used as reported by the authors was $3 \%$ of NS and $2 \%$ of Ni ferrite and $\mathrm{Cu}-\mathrm{Zn}$ ferrite by weight; beyond these amounts, the strength degraded. The results of flexural strength showed an increasing trend up to $3 \%$ replacement of nano-silica and $2 \%$ replacement of nano-ferrite (Fig. 7). Strength decreased at the higher ratios of nanoparticles, even though the flexural strength of concrete containing $4 \%$ of nanoparticles was still higher than the control concrete. The authors attributed this incline in strength to the rapid consumption of $\mathrm{Ca}(\mathrm{OH})_{2}$, which is one of the hydration products of the portland cement, by the highly reactive nanoparticles. The authors also indicated that an increase in modulus of elasticity of concrete with nanoparticles occurred up to a level of replacement of nanoparticles which is mentioned above and then decreased. This means stiffer concrete due to the presence of nanoparticles.

Palla et al. [45] stated that utilizing NS increased the splitting tensile strength of HSC. The strength increased by about $10 \%$ and $23 \%$ for $0.5 \%$ and $2 \%$ content of NS. The formation of extra C-S-H gel explained this increment due to the pozzolanic effect of silica nanoparticles [13]. In the study conducted by Ganesh et al. [46], silica nanoparticles were used as cement replacement at the dosages of $1 \%$ and $2 \%$ by weight in the production of HSC. The results revealed that the 28-day compressive strength could be enhanced by $8 \%$ and $18 \%$ compared to the control mix by the addition of $1 \%$ and $2 \%$ of nano-silica, respectively (Fig. 6). Lack of calcium hydroxide at the later ages ( 56 days) to react with unreacted silica nanoparticles caused the 56-day compressive strength to not be significantly higher than the 28-day compressive strength value. Higher consumption of calcium hydroxide by the reactive nano-silica particles at an early age was the reason for the low content of calcium hydroxide at later ages.

Palla et al. [45] reported that a $2 \%$ incorporation of NS decreased the water absorption by approximately $46 \%$ compared to the control concrete. According to the authors, higher water absorption of the sample concrete is due to the existence of more pores in the bulk paste and permeable surface, so the addition of NS leads to a denser microstructure; thus, fewer pores are available which makes concrete less permeable. Ganesh et al. [46] showed that chloride penetration of HSC can be reduced with the inclusion of NS particles due to the filling ability of $\mathrm{SN}$ which fills the pores in the mixture. Furthermore, the authors also stated that the addition of NS decreased water absorption of HSC through the formation of a denser structure due to the filling effect of NS particles.

Kumar et al. [35] revealed that compared to the control HSC, NS particles reduced the thermal conductivity of HSC by $11 \%, 18 \%, 22 \%$, and $15 \%$ at the various temperatures of $200^{\circ} \mathrm{C}, 400^{\circ} \mathrm{C}, 600^{\circ} \mathrm{C}$, and $800^{\circ} \mathrm{C}$, respectively. The authors stated that the weight loss of HSC samples containing NS particles was lower than the control specimens except for the specimens exposed to $400{ }^{\circ} \mathrm{C}$ which exhibited 3.5\% higher weight loss than the control HSC (Fig. 3). This behavior is explained by the disintegration of the $\mathrm{C}-\mathrm{S}-\mathrm{H}$ gels at high temperatures which causes the evaporation of the crystal water related to C-S-H gels. The lower weight loss of HSC samples having NS particles at higher temperatures of $600{ }^{\circ} \mathrm{C}$ and $800^{\circ} \mathrm{C}$ is attributed to the retardation 


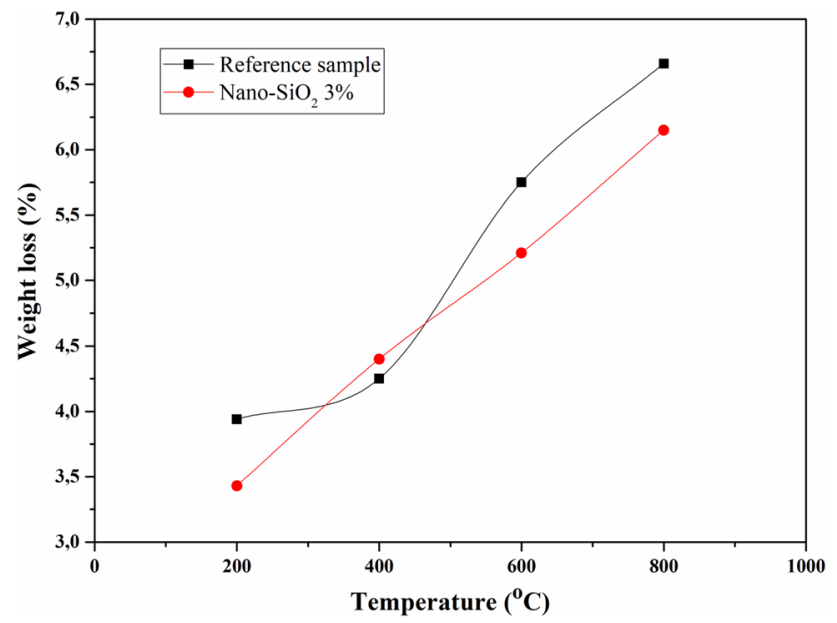

Fig. 3 Weight loss versus temperature for HSC samples [35]

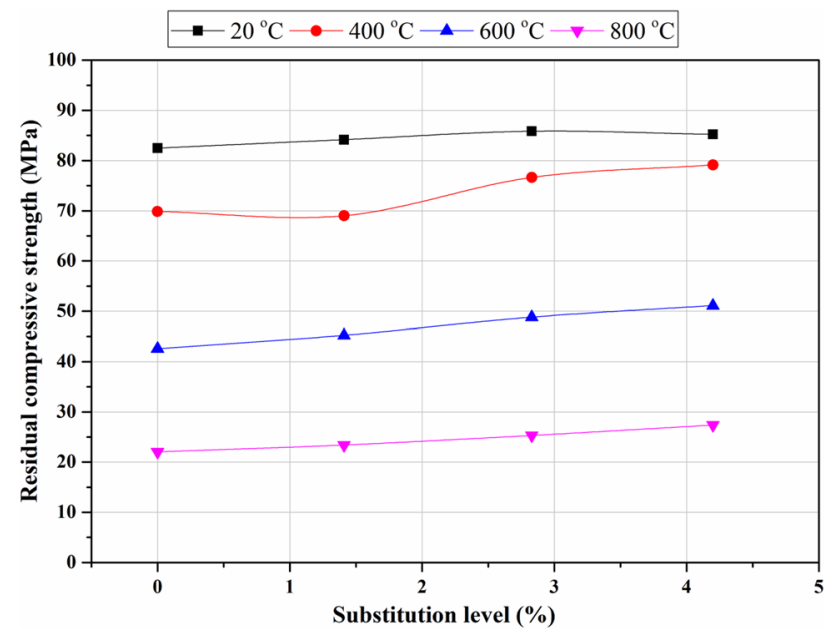

Fig. 4 Residual compressive strength with the substitution level of nanoparticles [47]

of the thermal degradation due to the formation of a more compact microstructure upon the addition of NS particles.

Effects of high temperatures on the performance of HSC incorporating NS particles were investigated in a study conducted by Bastami et al. [47]. Different dosages of NS were used together with silica fume. For HSC samples containing NS particles, the decrease in compressive strength was more pronounced at the elevated temperatures of $600-800{ }^{\circ} \mathrm{C}$, whereas for normal HSC concrete this range was $400-800^{\circ} \mathrm{C}$. Results of residual compressive strength indicated that with the increase in the content of NS the residual compressive strength increased at the elevated temperatures (Fig. 4). Residual compressive strength of HSC having $4.2 \%$ of NS (by mass) was $14.7 \%, 13 \%$, and $17.1 \%$ greater than that having $1.41 \%$ of NS at elevated temperatures of 400,600 , and $800^{\circ} \mathrm{C}$, respectively.

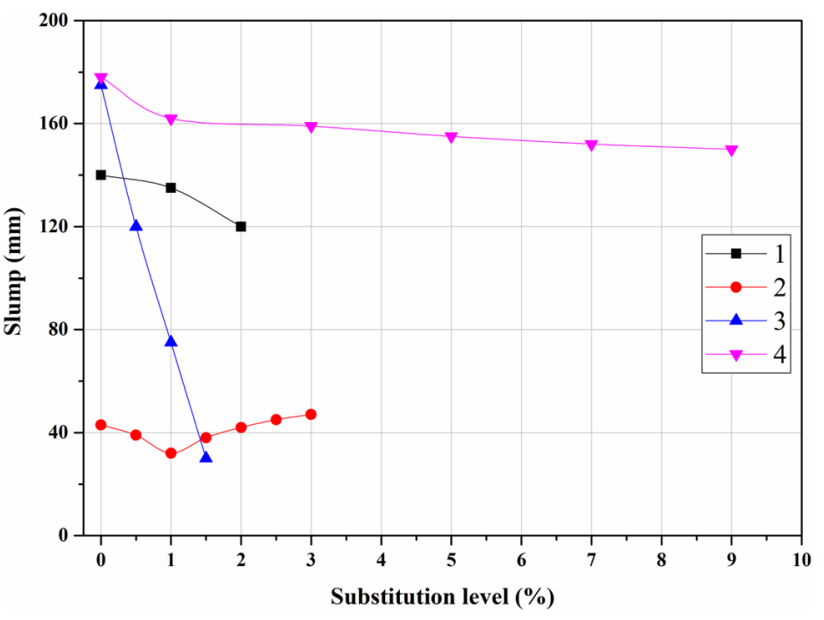

Fig. 5 Variation of slump of concrete with substitution level of nanoparticles: (1): nano- $\mathrm{CaCO}_{3}$ [18]; (2): nano- $\mathrm{SiO}_{2}$ [19]; (3): nano- $\mathrm{SiO}_{2}$ [30]; (4): nano-metakaolin [31]

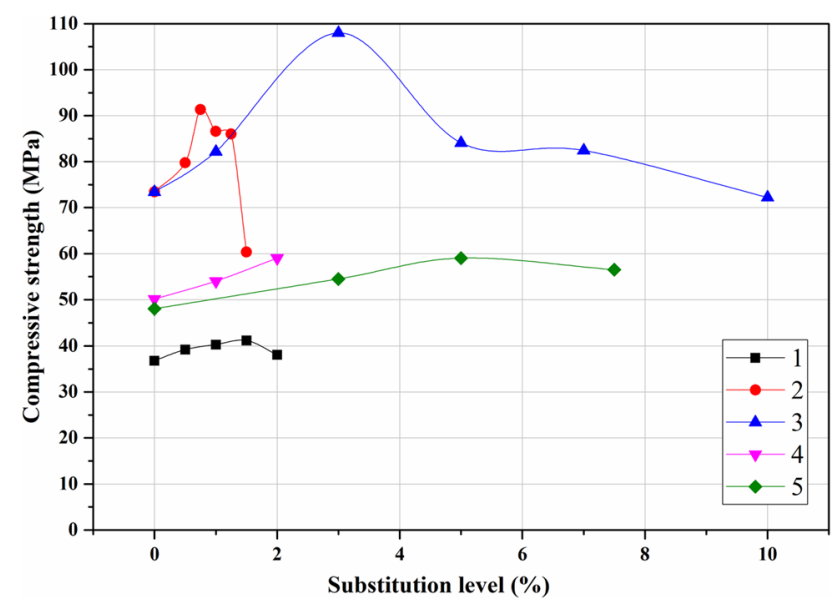

Fig. 6 Variation of 28-day compressive strength of concrete with substitution level of nanoparticles: (1): nano- $\mathrm{SiO}_{2}$ [12]; (2): nano$\mathrm{SiO}_{2}$ [25]; (3): nano-clay [25]; (4): nano-SiO 2 [46]; (5): nano-SiO 2 [51]

According to the studies reported in the literature, it can be seen that the addition of nanoparticles has a significant effect on the strength properties of HSC. This makes nanoparticles a favorable component in the production of HSC. Studies have also shown that the performance of HSC exposed to high temperature can be enhanced with the incorporation of various types of nanoparticles. Furthermore, durability-related properties such as water absorption and chloride ion penetration have improved in the HSC samples containing nanoparticles.

\subsection{Ultra-high-strength concrete (UHSC)}

Wu et al. [26] studied the behavior and effects of different kinds of nanomaterials, such as nano- $\mathrm{CaCO}_{3}(\mathrm{NC})$ and 


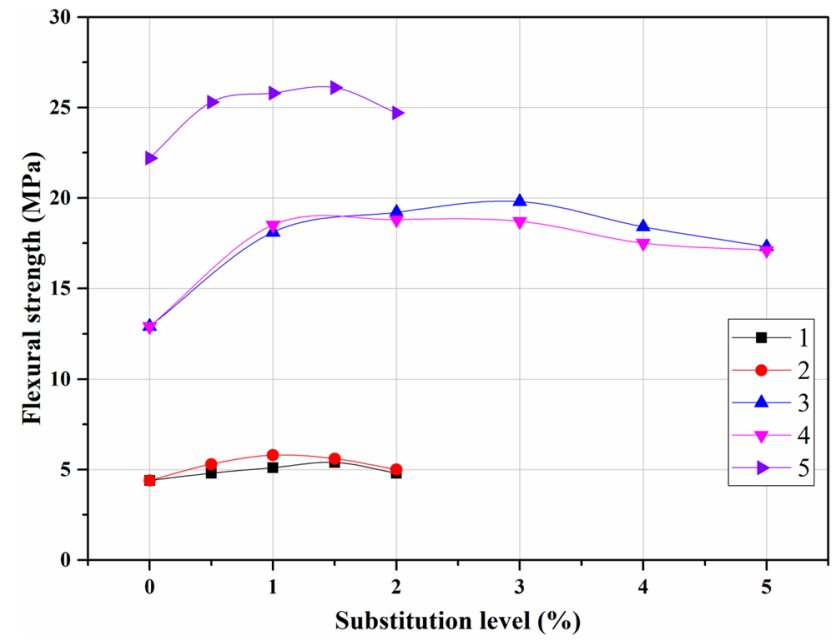

Fig. 7 Variation of 28-day flexural strength of concrete with substitution level of nanoparticles: (1) $80 \mathrm{~nm}$ nano-SiO2 [12]; (2): $15 \mathrm{~mm}$ nano- $\mathrm{SiO}_{2}$ [12]; (3): nano- $\mathrm{SiO}_{2}$ [13]; (4): nano-Ferrite [13]; (5): nano$\mathrm{CaCO}_{3}[27]$

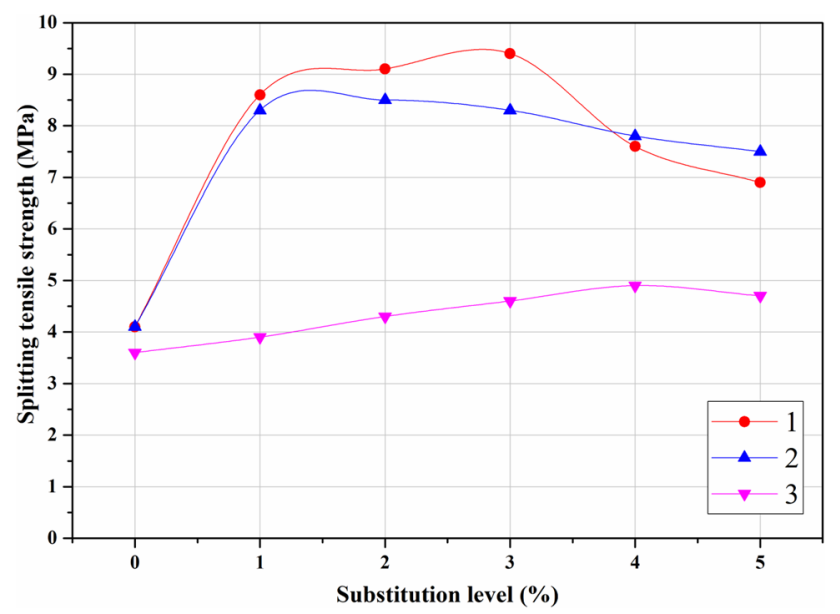

Fig. 8 Variation of 28-day splitting tensile strength of concrete with substitution level of nanoparticles: (1): nano- $\mathrm{SiO}_{2}$ [13]; (2): nano-ferrite [13]; (3): nano- $\mathrm{TiO}_{2}$ [21]

nano- $\mathrm{SiO}_{2}$ (NS) on the properties of ultra-high-strength concrete (UHSC). Different contents of nanomaterials by mass of cementitious materials were used in the study. The amounts used were $0,1.6 \%, 3.2 \%, 4.8 \%$ and $6.4 \%$ for NC and $0,0.5 \%, 1.5 \%$ and $2 \%$ for NS Test results exhibited an increase in the flexural strength in the range content between $1.6 \%$ and $4.8 \%$ of NC, but then strength decreased when the amount of NC increased up to $6.4 \%$ of NC. The flexural strength was $15 \%$ and $30 \%$ greater than the reference concrete for the content of $1.6 \%$ and $4.8 \%$ of NC, respectively, but in the amount of $6.4 \%$, the flexural strength reduced to a value lower than the reference concrete. Results of NS showed a similar trend to the
$\mathrm{NC}$ series. Flexural strength increased by 1-3 MPa for the content amount of $0.5-1.5 \%$ of NS, respectively, but then decreased to a value lower than the reference concrete at the amount of $2 \%$ of NS; this reduction was related to the gaps formed by the accumulation of NS particles [48]. The authors of this study also mentioned the difference in strength gain between NS and NC The early age strength $(1,3$, and 7 days) of the NS series was higher than that of NC; however, between 7 and 28 days, the strength of the NC series was higher than NS.

It can be concluded that the influence of different kinds of nanoparticles on the performance of UHSC may vary based on the type of nanoparticles. The effect of NS on the early age strength enhancement of UHSC was higher than that of NC, whereas the older age strength gain of NC was bigger than that of NS. This difference could be due to the difference in the rate of pozzolanic reactions of nanoparticles. Future studies may concern this issue by analyzing the rate of pozzolanic reaction on the strength enhancement at both early and old age. Hence better understandings of the effects of nanoparticles can be achieved.

\subsection{Other types of concrete}

Shaikh and Supit [18] reported the workability of high-volume fly ash (HVFA) concrete containing calcium carbonate $\left(\mathrm{CaCO}_{3}\right)$ nanoparticles. Results showed a reduction in the workability of concrete containing $\mathrm{CaCO}_{3}$ nanoparticles; moreover, reduction in the workability was more pronounced with higher percentages of $\mathrm{CaCO}_{3}$ nanoparticles as partial replacement of cement (Fig. 5). Isfahani et al. [30] stated that for $\mathrm{a} \mathrm{w} / \mathrm{b}$ ratio of 0.65 slump values of concrete showed a great decrease from 175 to $30 \mathrm{~mm}$ upon the inclusion of $1.5 \%$ NS (Fig. 5). This behavior was attributed to the reduction of the content of the lubricating water in the mixture due to the existence of NS particles which leads to the formation of a more viscous concrete [49] (Fig. $6)$.

Ivanchik et al. [11] utilized nano-silica with a particle size of about $100 \mathrm{~nm}$ for the modification of concrete. Compressive strength test results showed that $10 \%$ inclusion of nano-silica by weight of cement had the highest compressive strength value. The control specimen was destroyed under $63.5 \mathrm{kN}$, while the specimen with $10 \%$ was destroyed under 99.3kN. Naji Givi et al. [12] investigated the usability of nano- $\mathrm{SiO}_{2}$ as partial substitution of cement at the replacement levels of $0.5 \%, 1.0 \%, 1.5 \%$, and $2 \%$ on the enhancement of the mechanical properties of concrete. Results showed a higher compressive strength of samples produced with nano- $\mathrm{SiO}_{2}$ particles compared to control samples. The highest compressive strength value was measured at a replacement level of $1.5 \%$ and then decreased at the other percentages even though 
$2 \%$ replacement still showed a higher value than the control one (Fig. 6). The amount of nanoparticles more than required to react with lime during the hydration process causes excess silica to move out, which then leads to a reduction in strength [50]. Regarding flexural strength, the authors stated that the flexural strength of concrete samples incorporating $80 \mathrm{~nm}$ nano- $\mathrm{SiO}_{2}$ was lower than that of the samples having $15 \mathrm{~nm}$ nano-SiO ${ }_{2}$ (Fig. 7). The higher flexural strength of $15 \mathrm{~nm} \mathrm{SiO} 2$ particles could be attributed to the higher pozzolanic reactivity of $15 \mathrm{~nm}$ $\mathrm{SiO}_{2}$ particles than $80 \mathrm{~nm} \mathrm{SiO}{ }_{2}$ nanoparticles. Consequently, $15 \mathrm{~nm} \mathrm{SiO}_{2}$ particles lead to the formation of more hydrated products by accelerating the process of cement hydration [12]. Mohamed [25] investigated the effects of nanomaterials such as nano-silica and nano-clay on the mechanical properties of concrete. Concrete specimens were prepared with different contents of nanoparticles ranging from $0.5-10 \%$ as cement replacement by weight. Specimens were tested after 7, 28, and 90 days of curing. It was concluded from the results that nanoparticles had good improving effects on the compressive strength of concrete but using nanoparticles more than a certain amount harmed the compressive strength (Fig. 6). It was mentioned that using $3 \%$ of binary addition, including $75 \%$ nano-clay and 25\% nano-silica, showed the highest compressive strength value among all the specimens tested. Ren et al. [16] made an experimental study on the effects of $\mathrm{SiO}_{2}$ and $\mathrm{TiO}_{2}$ nanoparticles on the concrete's mechanical properties. Cement was replaced by nano- $\mathrm{SiO}_{2}$ and nano- $\mathrm{TiO}_{2}$ particles at the proportions of $1 \%, 3 \%$, and $5 \%$ by weight, and the produced concrete samples were tested at the ages of $3,7,21$, and 28 days. Results revealed that the addition of $\mathrm{SiO}_{2}$ nanoparticles improved the compressive strength of concrete. Samples containing NS had higher compressive strength than that of the reference sample at the early age of 3 and 7 days. This could be due to the fast completion of the hydration at the first 7 days of curing. Opposite of $\mathrm{SiO}_{2}$ nanoparticles, $\mathrm{TiO}_{2}$ nanoparticles did not have a remarkable effect on the concrete as they did not increase the compressive strength of concrete, only $3 \%$ addition of $\mathrm{TiO}_{2}$ nanoparticles increased compressive strength at the ages of 21 and 28 days (Fig. 8).

Madani et al. [51] stated that using nano-silica hydrosol with different specific surface areas $\left(100 \mathrm{~m}^{2} / \mathrm{g}, 200 \mathrm{~m}^{2} / \mathrm{g}\right.$, $300 \mathrm{~m}^{2} / \mathrm{g}$ ) improves the compressive strength of concrete at a very early age; this increase at the early age is related to the high pozzolanic reactivity of nano-silica and to the fact that nano-silica increases the rate of cement hydration. The effects of nano-silica decreased at the ages of 28 and 90 days; for example, the compressive strength of concrete produced with 3\% replacement of nano-silica with cement decreased from $42 \%$ at the early age to $6 \%$ at 28 and 90 days. Douba et al. [52] reported that the incorporation of different types of nanomaterials gave different elastic modulus values. They used different types of nanomaterials, such as multi-walled carbon nanotubes (MWCNTs), aluminum nanoparticles (ANP), and NS. Elastic modulus values were measured to be $14.29,10.30,8.74$, $15.09,6.23$, and $3.76 \mathrm{GPa}$ for reference concrete, MWCNT0.5 , ANP-0.5, ANP-2, NS-0.5, and NS-2, respectively. According to Fig. 9 , it can be noticed that $2 \%$ incorporation of ANP provided a higher elastic modulus than the reference concrete, while other ratios of incorporations demonstrated lower values than the reference one. The authors stated that the change in modulus of elasticity is mostly affected by the nanomaterial's chemical effect on the host matrix. Said et al. [32] stated that the addition of nanosilica significantly improved the tensile and compressive strength of concrete. The authors reported an increase in strength of about $14 \%$ and $18 \%$ with the incorporation of silica nanoparticles for the specimens produced with and without fly ash at the early curing age of 3 and 7 days, respectively. Enhancement in strength was attributed to the pozzolanic and filler effects of silica nanoparticles.

Studies conducted on the abrasion resistance of concrete reveal that abrasion resistance can be improved by improving compressive strength, curing conditions, production techniques, aggregate properties, and testing conditions $[53,54]$. In an experimental study conducted by $\mathrm{Li}$ et al. [22] effects of incorporating nano- $\mathrm{TiO}_{2}$, nano$\mathrm{SiO}_{2}$, and polypropylene fibers on the abrasion resistance of concrete were investigated. They reported an enhancement in the abrasion resistance upon the addition of nanoparticles. It is stated that as the contents of nano- $\mathrm{TiO}_{2}$ and nano- $\mathrm{SiO}_{2}$ increase, their effect on the abrasion resistance decreases. The surface index and side index of abrasion resistance were improved by $180.7 \%$ and $173.3 \%$ for the

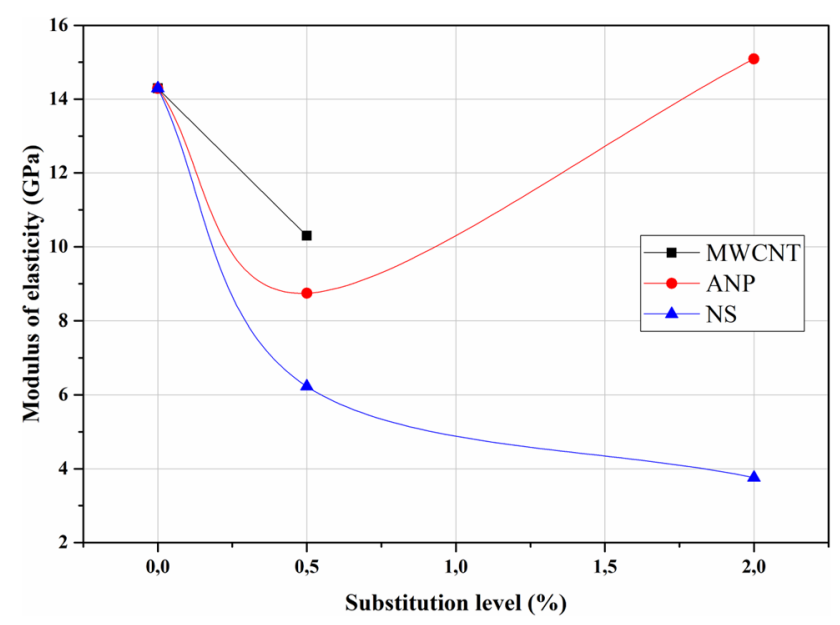

Fig. 9 Variation of modulus of elasticity with a substitution level of nanoparticles [52] 
concrete sample containing $1 \%$ of nano- $\mathrm{TiO}_{2}$ by weight of the binder (Fig. 10), whereas these improvements were measured to be $157 \%$ and $139.4 \%$ for surface index and side index of abrasion resistance upon the addition of $1 \%$ of nano- $\mathrm{SiO}_{2}$. The decline in the abrasion resistance with the increasing amount of nanoparticles could be attributed to the distance of nanoparticles at high amounts. As the amount of nanoparticles increases, the distance between them decreases which leaves less space for the growth of $\mathrm{Ca}(\mathrm{OH})_{2}$ crystal; this causes less formation of $\mathrm{C}-\mathrm{S}-\mathrm{H}$ gel and hence weaker microstructure of the concrete matrix, consequently less strength and resistance to abrasion.

Salemi and Behfarnia [23] stated that the incorporation of nanoparticles to concrete increased the resistance against freezing and thawing. The strength loss of compressive strength was reduced by $16.28 \%$ and $18.19 \%$ for concrete samples containing $5 \%$ NS and 3\% nanoalumina, respectively. The authors also reported that $5 \%$ NS and 3\% nano-alumina exhibited the highest freezing and thawing resistance among all other specimens since they had the lowest strength loss values. The decrease in length was measured to be $28.1 \%$ for concrete specimens, and it decreased to $3.81 \%$ and $1.41 \%$ with the addition of 5\% NS and 3\% nano-alumina, respectively. Zhao et al. [17] pointed out the relationship between water-cement ratio and frost resistance and stated that frost resistance decreased as the water-cement ratio decreased. They reported that a decrease in the capillary voids occurred due to the addition of NS, and thus, freezing and thawing resistance of concrete developed. Frost resistance of concrete containing NS particles increased by $28 \%$ when compared to traditional concrete. Olivier et al. [15] studied the effects of incorporating nanoparticles such as NS on the shrinkage crack behavior of concrete. It was

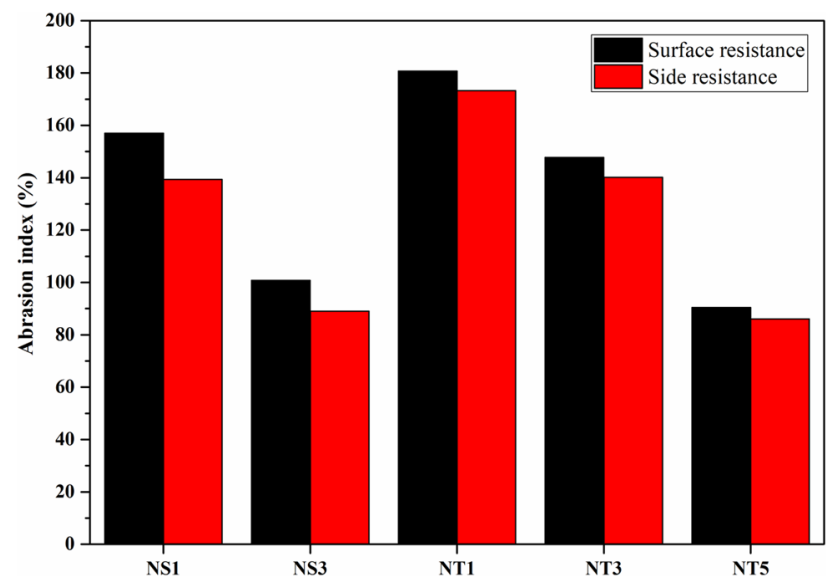

Fig. 10 Abrasion resistance of samples containing nano- $\mathrm{SiO}_{2}$ and nano- $\mathrm{TiO}_{2}$ [22] noticed that NS accelerated drying time enhanced by the reduced bleeding, this led to the initiation of the plastic shrinkage cracking, and hence plastic shrinkage occurred. The authors reported that plastic shrinkage behavior for concrete containing NS was different from conventional concrete. In NS specimens before plastic shrinkage, a crack occurred, which is a sign of settlement, while in conventional concrete plastic settlement occurred first and reached maximum before any noticeable plastic shrinkage happened. Gao et al. [29] studied the effects of nanoparticles such as NS and nano-silicon carbide (NSC) on the drying shrinkage of road fly ash concrete. The increment in the drying shrinkage rate of road fly ash concrete was $124.8 \%$ and $85 \%$ for $2 \%$ of both NS and NSC, respectively, in comparison to the reference concrete.

Isfahani et al. [30] stated that the addition of NS to concrete could exhibit different effects with different water/ binder $(\mathrm{w} / \mathrm{b})$ ratios. They concluded that with increasing $\mathrm{w} / \mathrm{b}$ to 0.65 , the carbonation coefficient $(\mathrm{K})$ increased to a maximum of $29.3 \mathrm{~mm} /$ year $^{0.5}$ from $24 \mathrm{~mm} /$ year $^{0.5}$ for the incorporation of $1 \%$ of NS. In comparison, $\mathrm{K}$ decreased to a maximum of $16 \mathrm{~mm} /$ year $^{0.5}$ from $20.8 \mathrm{~mm} /$ year $^{0.5}$ for a $1 \%$ addition of NS at w/b of 0.55 . Shaikh and Supit [18] conducted rapid chloride penetration test (RCPT). Results exhibited improved performance of normal and high-volume fly ash (HVFA) concretes containing $\mathrm{CaCO}_{3}$ nanoparticles against chloride ingress. $1 \%$ replacement of $\mathrm{CaCO}_{3}$ nanoparticles with cement increased the resistance of both ordinary and HVFA concretes against chloride ion penetration by $20 \%$ and $18 \%$, respectively, at 28 days. The authors mentioned that the longer the curing period, the lower the total charge passes through the concrete specimens; this is attributed to the pozzolanic reactions of $\mathrm{CaCO}_{3}$ nanoparticles.

Presented results reveal that the addition of nanoparticles can significantly improve the mechanical and durability-related properties of different types of concrete. However, the workability of concrete is reduced with the incorporation of nanoparticles. It can be concluded from the studies that at high amounts of inclusion effects of nanoparticles decrease. This is a challenging issue that most researchers face. At high amounts, agglomeration of nanoparticles occurs, which leads to the formation of weak area zones in the matrix.

\section{Dispersion of nanoparticles in the host matrix and morphology}

The dispersion state of nanoparticles in the cement matrix has a significant role in the properties and the performance of the produced composite. The non-uniform dispersion of nanoparticles in the cement matrix 
causes the agglomeration of them which then leads to the formation of weak areas in the composite [28]. Thus, it is important to avoid the agglomeration of nanoparticles to produce a cement-based mixture with high performance [55]. Due to the agglomeration of nanoparticles, some parts of their surface stick to each other causing them been unable to react, hence reducing the reactivity of nanoparticles [3]. According to Niewiadomski et al. [42], non-uniform dispersion of nanoparticles in the matrix and inappropriate addition method can be considered as the reasons for obtaining unfavorable mechanical properties.

Some researchers [55-57] recommend a well dispersion of nanoparticles before mixing with other constituents. In some investigations, ultrasonication was used to disperse nano-powders either with or without any dispersing agent [8, 57-62]. Reches et al. [9] stated that despite the existence of the microscale agglomerates, an improvement in the strength occurred with the inclusion of $\mathrm{TiO}_{2}$ nanoparticles. This enhancement was attributed to the role of nanoparticles as nucleation sites. Ganesh et al. [46] used a sonicator to disperse the amorphous nano-silica in the surfactant-like superplasticizer with the addition of water. The research showed that 56-day compressive strength was not considerably higher than the 28-day compressive strength. The authors contributed this to the poor dispersion of silica nanoparticles in the cement matrix.

Du et al. [59] reported the challenges of dispersing nano-silica particles in the mixture due to the microscalediameter agglomeration of silica nanoparticles (Fig. 11). To overcome this challenge and to obtain an aqueous solution of nano-silica, the surfactant and ultrasonication were applied. Haruehansapong et al. [63] pointed out the effects of weak dispersion of NS particles on the improvements of compressive strength. Compressive strength of the mixture produced with $40 \mathrm{~nm}$ NS particles was greater than those produced with 12 and $20 \mathrm{~nm}$ NS particles. Smaller nanoparticles lead to the formation of agglomerations and hence result in poor distribution.
According to Kawashima et al. [58], utilization of surfactants like polycarboxylate plays a significant role in the dispersion of nano- $\mathrm{CaCO}_{3}$ in an aqueous solution. The authors stated that by changing the architecture of the polymer, better adsorption and dispersion can be obtained. The physical break-up of nanoparticles by the sonication process results in an improved dispersion of nanoparticles and consequently enhances the early age (7-day) strength gain of the fly ash cement paste [58].

Microstructural studies revealed that by incorporating silica nanoparticles a more compact and denser microstructure of concrete can be obtained compared to the concrete produced without nano-silica particles $[64,65]$. The utilization of nano-silica significantly improves the hydration process of the cement through the generation of more hydrated products such as C-S-H gel $[19,49,66]$. According to the findings of Khaloo et al. [34], the specific surface area of nanoparticles has a significant effect on the properties of the matrix. Silica nanoparticles with higher specific surface areas $\left(380 \mathrm{~m}^{2} / \mathrm{g}\right)$ are more likely to form agglomerates than silica nanoparticles with a specific surface area of $200 \mathrm{~m}^{2} / \mathrm{g}$. As it can be observed from Fig. 12, larger volumes and dimensions of agglomerates exist in the matrix of the HPC produced with NS380 than the HPC with NS200. NS200 led to the formation of a denser structure than NS380 and hence enhanced the strength of the matrix. Du et al. [59] indicated that the incorporation of silica nanoparticles led to the formation of a homogenous microstructure and filled the gaps in the interfacial transition zone (ITZ). The authors also stated that mechanical and durability-related properties of concrete could be enhanced by densifying the ITZ phase in concrete which is possible through the utilization of silica nanoparticles.

Yu et al. [49] reported the existence of a large amount of $\mathrm{Ca}(\mathrm{OH})_{2}$ along with a porous structure for the UHPC sample produced without silica nanoparticles (Fig. 13a). Modifying the UHPC with $4 \%$ of nano-silica improved the microstructure and impermeability of the UHPC by producing more $\mathrm{C}-\mathrm{S}-\mathrm{H}$ gel from the pozzolanic reaction of
Fig. 11 SEM micrographs of silica nanoparticles [59]: a: agglomeration of nano-silica particles; b: high magnification of silica nanoparticles (a)

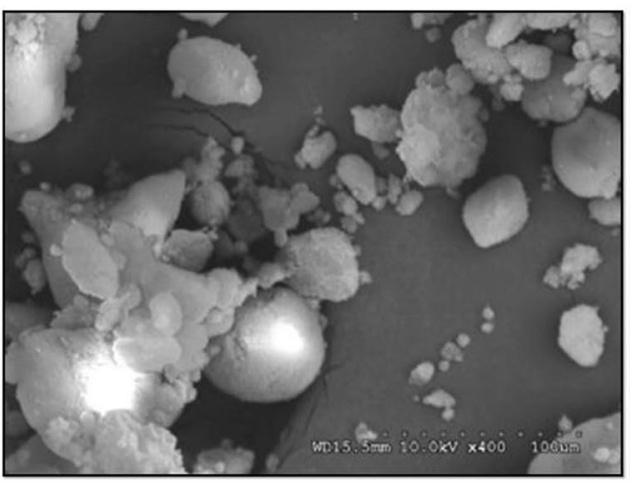

(b)

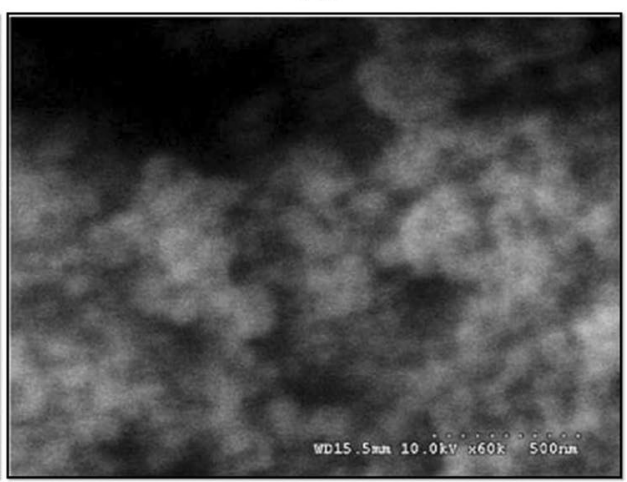


Fig. 12 SEM micrographs [34]: a: agglomerates in the pores of HPC NS200; b agglomerates in the pores of HPC NS380 (a)
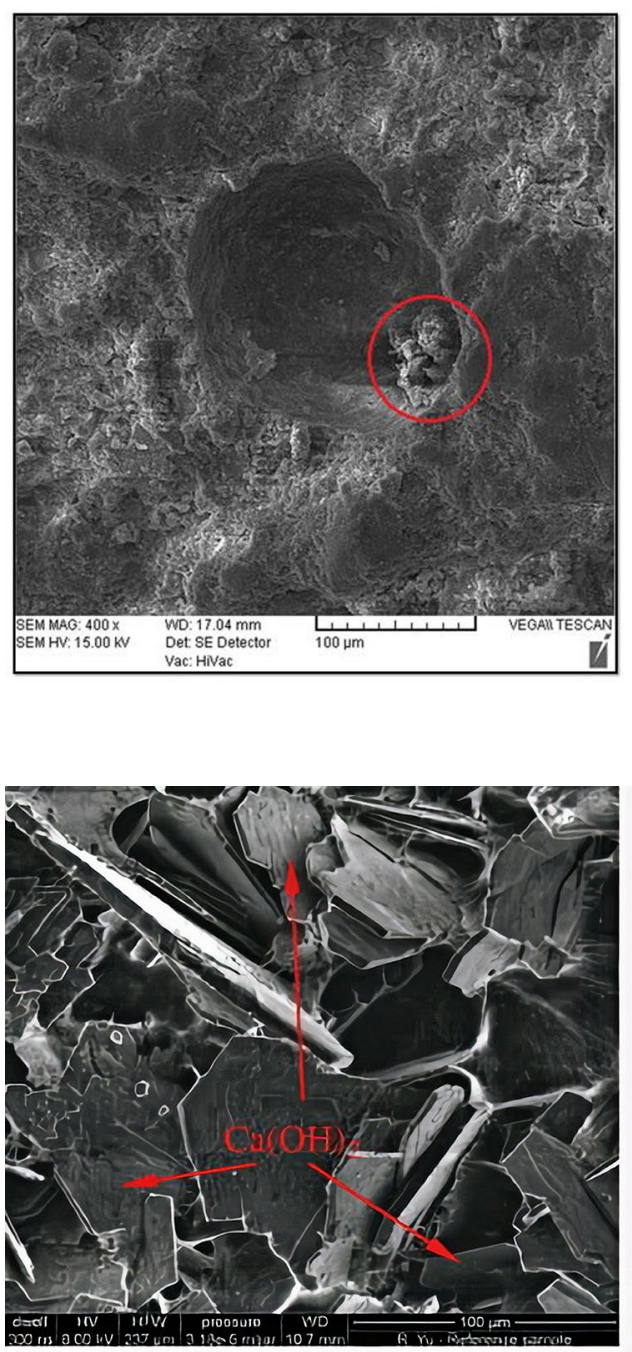

(a) (b)
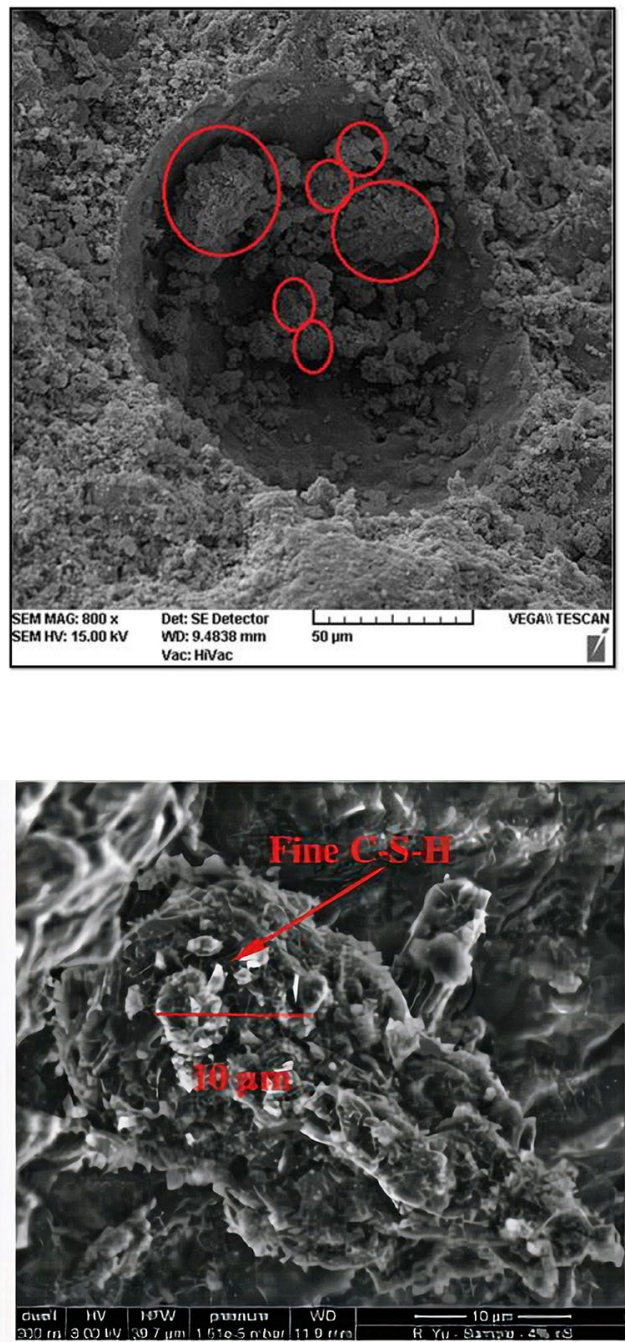

(b)

Fig. 13 SEM micrographs [49]: $\mathbf{a}$ : control specimen; $\mathbf{b}$ : UHPC with $4 \%$ of nano-silica; c: UHPC with $5 \%$ of nano-silica

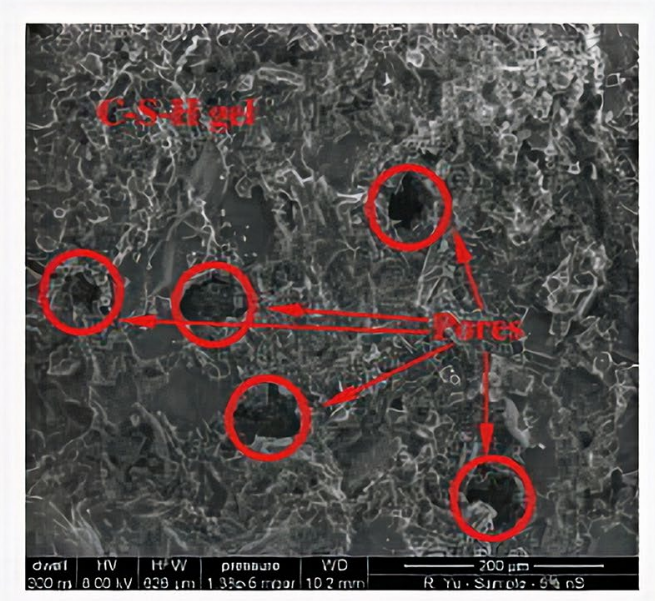

(c) 
silica nanoparticles with $\mathrm{Ca}(\mathrm{OH})_{2}$ (Fig. 13b). However, the addition of more silica nanoparticles increased the porosity of the UHPC since greater nano-silica causes the mixture to be more viscous (Fig. 13c).

Figure 14 shows the microstructure of the SCC produced with and without the inclusion of clay nanoparticles [33]. Scanning electron microscope (SEM) images show the existence of $\mathrm{C}-\mathrm{S}-\mathrm{H}$ gel accompanied by high volumes of ettringite and $\mathrm{Ca}(\mathrm{OH})_{2}$ in the control sample (Fig. 14a). The addition of $0.5 \%$ of clay nanoparticles enhanced the microstructure of SCC, and a good dispersion of clay nanoparticles can be observed in the matrix which leads to the generation of a more compacted microstructure (Fig. 14b). The effects of small sizes of clay nanoparticles on the filling pores and formation of a denser microstructure of SCC can be seen in Fig. $14 \mathrm{c}$ for the concrete sample containing 0.5 of nano-clay. Formation of C-S-H gels can be seen in the sample with nano-clay content of $0.5 \%$ (Fig. 14d). Produced C-S-H gels play a significant role as they enhance the bond between clay nanoparticles and the cement paste. Increasing the dosage of clay nanoparticles to $1 \%$ caused the formation of agglomeration (Fig. 14e and f).

One of the main concerns regarding applications of nanoparticles in concrete is the dispersion state. Presented studies have shown that as the particle size of nanomaterials gets smaller, their tendency to stick together and form agglomerations gets higher. To overcome this challenge, different dispersion methods such as mechanical stirring $[67,68]$, ball milling [58], high shear mixing [69], and ultrasonication [8, 57-62] have been used. These methods are known to be effective in breaking down the agglomerated particles into smaller parts so that their dispersion in the matrix becomes easier. Microstructural studies have revealed that the microstructure of concrete can be greatly enhanced with the addition of nanoparticles. This could be due to the pozzolanic effects of nanoparticles during the hydration process which then lead to the formation of more $\mathrm{C}-\mathrm{S}-\mathrm{H}$ gels.

\section{Conclusions}

This study has provided a detailed review of the utilization of nanoparticle materials in different types of concrete. Fresh-state, mechanical, and durability-related properties of cementitious materials were discussed, and conclusions are given below:

(1) The incorporation of nanoparticles with high surface areas and finer particle sizes than cement requires more amount of water to maintain the workability and hence negatively affects the workability of the mixture.

(2) Improve in compressive strength can be noticed with an increase in the replacement ratio of nanoparticles. This is due to the enhanced hydration and (a)

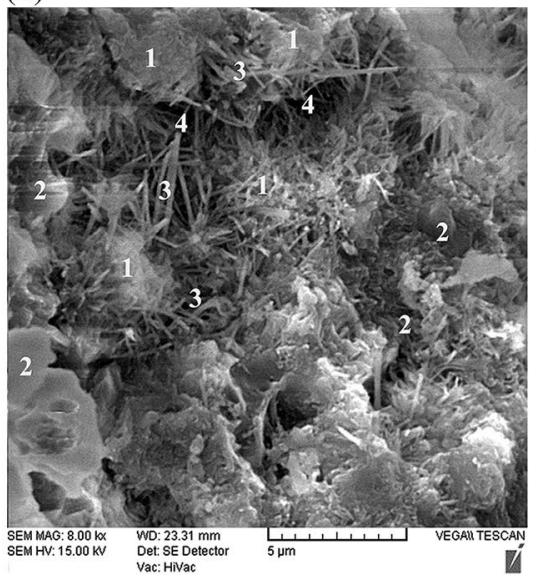

(d)

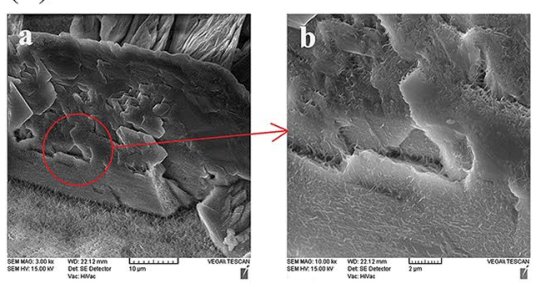

(b)

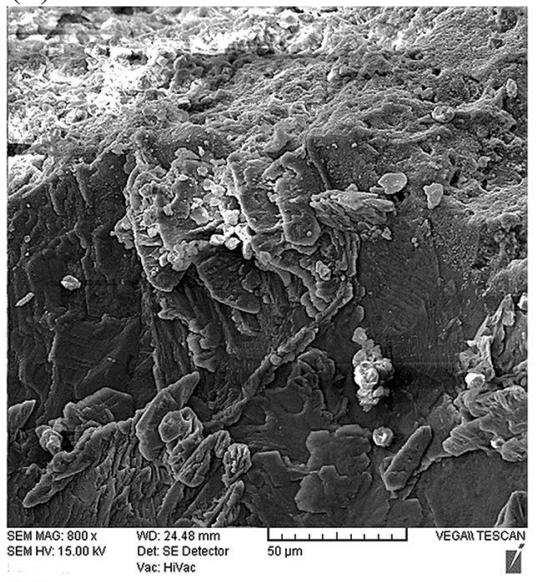

(e)
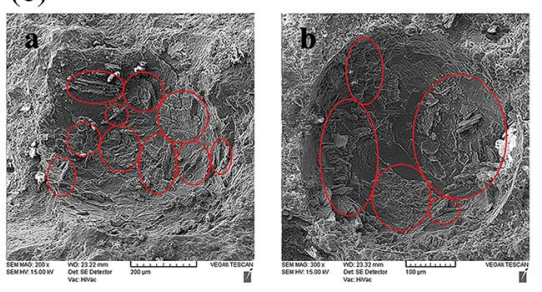

(c)

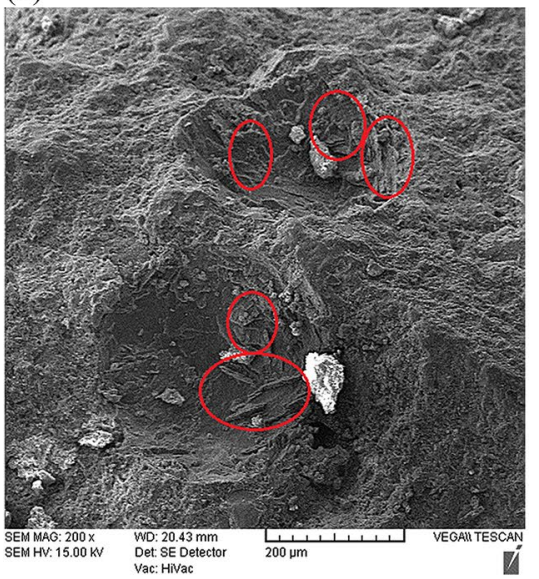

(f)
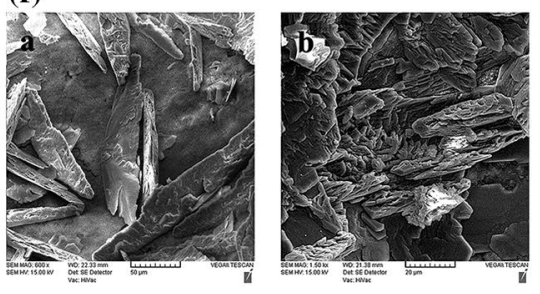

Fig. 14 SEM micrographs of SCC concrete produced with and without clay nanoparticles [33]: a: control specimen. $1=\mathrm{C}-\mathrm{S}-\mathrm{H}$, $2=\mathrm{Ca}(\mathrm{OH})_{2}, 3=$ ettringite, $4=$ pore; $\mathbf{b}$ : arrangement of nano-clays in the SCC sample with $0.5 \%$ of clay nanoparticles; c: pore-filling effect of clay nanoparticles; $\mathbf{d}$ nano-clay agglomerates and $\mathrm{C}-\mathrm{S}-\mathrm{H}$ gels on the surface of agglomerates; e,f: existence of nano-clay agglomerates in the specimen containing $1 \%$ nano-clay particles

\section{SN Applied Sciences}


the formation of a more compacted microstructure with the inclusion of finely dispersed nanoparticles. It can be concluded that strength gain is observed mostly at an early age.

(3) The incorporation of different nanoparticles enhances and increases the flexural strength up to an optimal amount. At the higher dosages of inclusion of nanoparticles, the flexural strength tends to decrease when the amount surpasses the threshold.

(4) An increase in splitting tensile strength with the incorporation of nanoparticles has been noticed. This can be due to the improved microstructure of the mix due to the incorporation of nanoparticles which cause a refinement of the microstructure.

(5) The addition of nanomaterials has developed the modulus of elasticity to a good level. The chemical effects of nanoparticles on the matrix influence the modulus of elasticity.

(6) Water absorption of concrete modified with nanoparticles was reduced. The fine particle size of nanoparticles fills the pores in the hardened cement paste and hence creates a denser and less permeable structure. Nanoparticles with smaller particle size better improve the impermeability of the mixture than the nanoparticles with the greater particle size.

(7) Nanoparticles reduce the permeability of cementitious mixtures against chloride ions; thus, lower values of chloride ion penetration can be seen with the incorporation of nanoparticles.

(8) The inclusion of nano-scaled particles improves the resistance against freezing and thawing. Using 5\% of nano-silica and $3 \%$ of nano-alumina reduced the loss of compressive strength by $16.28 \%$ and $18.19 \%$, respectively.

(9) Various types of nanomaterials impose different effects on the shrinkage property of the mixture.

(10) The carbonation depth of concrete can obtain different values with different types of nanoparticles.

(11) The microstructure of different types of concrete is significantly enhanced upon the addition of nanoparticles since nanoparticles improve the hydration process by producing more hydrated products.

\section{Future trends}

The findings of this paper indicate that the properties of different types of concrete can be significantly improved with the incorporation of the various types of nanoparticles. One of the main challenges regarding the incorporation of nanoparticles is the dispersion of them in the matrix. Future studies should focus on finding innovative methods to provide a uniform dispersion of nanoparticles and avoid the formation of agglomerates. Further studies on the workability of nanoparticle-induced concrete are recommended so that the optimum amount of required superplasticizer can be determined. Using nanoparticles in fewer amounts accompanied by waste materials such as plastic aggregates or plastic fibers can be an attractive research study. Further researches can be made on the properties of cement-based materials containing both nanoparticles and waste plastic materials to examine longterm properties and improve sustainability. This topic is essential regarding environmental issues due to the accumulation of waste plastic materials.

\section{Declaration}

Conflict of interest The authors declare that they have no conflict of interest.

Open Access This article is licensed under a Creative Commons Attribution 4.0 International License, which permits use, sharing, adaptation, distribution and reproduction in any medium or format, as long as you give appropriate credit to the original author(s) and the source, provide a link to the Creative Commons licence, and indicate if changes were made. The images or other third party material in this article are included in the article's Creative Commons licence, unless indicated otherwise in a credit line to the material. If material is not included in the article's Creative Commons licence and your intended use is not permitted by statutory regulation or exceeds the permitted use, you will need to obtain permission directly from the copyright holder. To view a copy of this licence, visit http://creativecommons. org/licenses/by/4.0/.

\section{References}

1. Shi C, Jiménez AF, Palomo A (2011) New cements for the 21st century: the pursuit of an alternative to portland cement. Cem Concr Res 41:750-763. https://doi.org/10.1016/j.cemconres. 2011.03.016

2. Pacheco-Torgal F, Miraldo S, Ding Y, Labrincha JA (2013) Targeting HPC with the help of nanoparticles: an overview. Constr Build Mater 38:365-370. https://doi.org/10.1016/j.conbuildmat. 2012.08.013

3. Reches Y (2018) Nanoparticles as concrete additives: review and perspectives. Constr Build Mater 175:483-495. https://doi.org/ 10.1016/j.conbuildmat.2018.04.214

4. Drexler E, Peterson C, Pergamit G, Brand S (1993) Unbounding the future: the nanotechnology revolution. Precis Eng 15:306. https://doi.org/10.1016/0141-6359(93)90208-r

5. Stein HN, Stevels JM (2007) Influence of silica on the hydration of $3 \mathrm{CaO}$, SiO2. J Appl Chem 14:338-346. https://doi.org/10.1002/ jctb.5010140805

6. Zhang P, Wan J, Wang K, Li Q (2017) Influence of nano-SiO2 on properties of fresh and hardened high performance concrete: a state-of-the-art review. Constr Build Mater 148:648-658. https:// doi.org/10.1016/j.conbuildmat.2017.05.059 
7. Jo BW, Kim CH, TaePark GHJB (2007) Characteristics of cement mortar with nano-SiO2 particles. Constr Build Mater 21:13511355. https://doi.org/10.1016/j.conbuildmat.2005.12.020

8. Li W, Long C, Tam VWY, Poon CS, Hui Duan W (2017) Effects of nano-particles on failure process and microstructural properties of recycled aggregate concrete. Constr Build Mater 142:42-50. https://doi.org/10.1016/j.conbuildmat.2017.03.051

9. Reches $Y$, Thomson K, Helbing M, Kosson DS, Sanchez F (2018) Agglomeration and reactivity of nanoparticles of $\mathrm{SiO} 2, \mathrm{TiO} 2$, $\mathrm{Al2O} 3, \mathrm{Fe} 2 \mathrm{O} 3$, and clays in cement pastes and effects on compressive strength at ambient and elevated temperatures. Constr Build Mater 167:860-873. https://doi.org/10.1016/j.conbu ildmat.2018.02.032

10. Monasterio M, Gaitero JJ, Erkizia E, Guerrero Bustos AM, Miccio LA, Dolado JS, Cerveny S (2015) Effect of addition of silica- and amine functionalized silica-nanoparticles on the microstructure of calcium silicate hydrate (C-S-H) gel. J Colloid Interface Sci 450:109-118. https://doi.org/10.1016/j.jcis.2015.02.066

11. Ivanchik N, Kondratiev V, Chesnokova A (2016) Use of nanosilica recovered from the finely dispersed by-product of the electrothermal silicon production for concrete modification. Procedia Eng 150:1567-1573. https://doi.org/10.1016/j.proeng.2016.07. 119

12. Naji Givi A, Abdul Rashid S, Aziz FNA, Salleh MAM (2010) Experimental investigation of the size effects of $\mathrm{SiO} 2$ nano-particles on the mechanical properties of binary blended concrete. Compos Part B Eng 41:673-677. https://doi.org/10.1016/j.compositesb. 2010.08.003

13. Amin M, Abu El-Hassan K (2015) Effect of using different types of nano materials on mechanical properties of high strength concrete. Constr Build Mater 80:116-124. https://doi.org/10. 1016/j.conbuildmat.2014.12.075

14. Askari Dolatabad Y, Kamgar R, Gouhari Nezad I (2020) Rheological and mechanical properties, acid resistance and water penetrability of lightweight self-compacting concrete containing nano-SiO2, nano-TiO2 and nano-Al2O3. Iran J Sci Technol-Trans Civ Eng 44:603-618. https://doi.org/10.1007/ s40996-019-00328-1

15. Olivier G, Combrinck R, Kayondo M, Boshoff WP (2018) Combined effect of nano-silica, super absorbent polymers, and synthetic fibres on plastic shrinkage cracking in concrete. Constr Build Mater 192:85-98. https://doi.org/10.1016/j.conbuildmat. 2018.10.102

16. Ren J, Lai Y, Gao J (2018) Exploring the influence of SiO2 and $\mathrm{TiO} 2$ nanoparticles on the mechanical properties of concrete. Constr Build Mater 175:277-285. https://doi.org/10.1016/j. conbuildmat.2018.04.181

17. Zhao Z, Kong J, Yang $H$ (2012) Study on frost resistance of nano SiO2 cement concrete. Appl Mech Mater 198-199:48-51

18. Shaikh FUA, Supit SWM (2014) Mechanical and durability properties of high volume fly ash (HVFA) concrete containing calcium carbonate $(\mathrm{CaCO} 3)$ nanoparticles. Constr Build Mater 70:309321. https://doi.org/10.1016/j.conbuildmat.2014.07.099

19. Chithra S, Senthil Kumar SRR, Chinnaraju K (2016) The effect of colloidal nano-silica on workability, mechanical and durability properties of high performance concrete with copper slag as partial fine aggregate. Constr Build Mater 113:794-804. https:// doi.org/10.1016/j.conbuildmat.2016.03.119

20. Rong Z, Sun W, Xiao H, Jiang G (2015) Effects of nano-SiO2 particles on the mechanical and microstructural properties of ultra-high performance cementitious composites. Cem Concr Compos 56:25-31. https://doi.org/10.1016/j.cemconcomp.2014. 11.001

21. Jalal M, Ramezanianpour AA, Pool MK (2013) Split tensile strength of binary blended self compacting concrete containing low volume fly ash and $\mathrm{TiO}_{2}$ nanoparticles. Compos Part B
Eng 55:324-337. https://doi.org/10.1016/j.compositesb.2013. 05.050

22. Li H, Zhang MH, Ou JP (2006) Abrasion resistance of concrete containing nano-particles for pavement. Wear 260:1262-1266. https://doi.org/10.1016/j.wear.2005.08.006

23. Salemi N, Behfarnia K (2013) Effect of nano-particles on durability of fiber-reinforced concrete pavement. Constr Build Mater 48:934-941. https://doi.org/10.1016/j.conbuildmat.2013.07.037

24. Sobolev K (2015) Nanotechnology in Construction. Nanotechnol Constr. https://doi.org/10.1007/978-3-319-17088-6

25. Mohamed AM (2016) Influence of nano materials on flexural behavior and compressive strength of concrete. HBRC J 12:212225. https://doi.org/10.1016/j.hbrcj.2014.11.006

26. Wu Z, Shi C, Khayat KH, Wan S (2016) Effects of different nanomaterials on hardening and performance of ultra-high strength concrete (UHSC). Cem Concr Compos 70:24-34. https://doi.org/ 10.1016/j.cemconcomp.2016.03.003

27. Li W, Huang Z, Cao F, Sun Z, Shah SP (2015) Effects of nano-silica and nano-limestone on flowability and mechanical properties of ultra-high-performance concrete matrix. Constr Build Mater 95:366-374. https://doi.org/10.1016/j.conbuildmat.2015.05.137

28. Ghafari E, Costa H, Júlio E, Portugal A, Durães L (2014) The effect of nanosilica addition on flowability, strength and transport properties of ultra high performance concrete. Mater Des 59:1-9. https://doi.org/10.1016/j.matdes.2014.02.051

29. Gao Y, He B, Li Y, Tang J, Qu L (2017) Effects of nano-particles on improvement in wear resistance and drying shrinkage of road fly ash concrete. Constr Build Mater 151:228-235. https://doi. org/10.1016/j.conbuildmat.2017.06.080

30. Isfahani FT, Redaelli E, Lollini F, Li W, Bertolini L (2016) effects of nanosilica on compressive strength and durability properties of concrete with different water to binder ratios. Adv Mater Sci Eng. https://doi.org/10.1155/2016/8453567

31. Muhd Norhasri MS, Hamidah MS, Mohd Fadzil A, Megawati O (2016) Inclusion of nano metakaolin as additive in ultra high performance concrete (UHPC). Constr Build Mater 127:167-175. https://doi.org/10.1016/j.conbuildmat.2016.09.127

32. Said AM, Zeidan MS, Bassuoni MT, Tian Y (2012) Properties of concrete incorporating nano-silica. Constr Build Mater 36:838844. https://doi.org/10.1016/j.conbuildmat.2012.06.044

33. Hosseini P, Afshar A, Vafaei B, Booshehrian A, Molaei Raisi E, Esrafili A (2017) Effects of nano-clay particles on the short-term properties of self-compacting concrete. Eur J Environ Civ Eng 21:127-147. https://doi.org/10.1080/19648189.2015.1096308

34. Khaloo A, Mobini MH, Hosseini P (2016) Influence of different types of nano-SiO2 particles on properties of high-performance concrete. Constr Build Mater 113:188-201. https://doi.org/10. 1016/j.conbuildmat.2016.03.041

35. Kumar R, Singh S, Singh LP (2017) Studies on enhanced thermally stable high strength concrete incorporating silica nanoparticles. Constr Build Mater 153:506-513. https://doi.org/10. 1016/j.conbuildmat.2017.07.057

36. Mirgozar Langaroudi MA, Mohammadi Y (2018) Effect of nanoclay on workability, mechanical, and durability properties of self-consolidating concrete containing mineral admixtures. Constr Build Mater 191:619-634. https://doi.org/10.1016/j. conbuildmat.2018.10.044

37. Quercia G, Spiesz P, Hüsken G, Brouwers HJH (2014) SCC modification by use of amorphous nano-silica. Cem Concr Compos 45:69-81. https://doi.org/10.1016/j.cemconcomp.2013.09.001

38. Jalal M, Pouladkhan A, Harandi OF, Jafari D (2015) Comparative study on effects of Class F fly ash, nano silica and silica fume on properties of high performance self compacting concrete. Constr Build Mater 94:90-104. https://doi.org/10.1016/j.conbu ildmat.2015.07.001 
39. Joshaghani A, Balapour M, Mashhadian M, Ozbakkaloglu $T$ (2020) Effects of nano-TiO2, nano-Al2O3, and nano-Fe2O3 on rheology, mechanical and durability properties of self-consolidating concrete (SCC): an experimental study. Constr Build Mater 245:118444. https://doi.org/10.1016/j.conbuildmat.2020. 118444

40. Guang Y, Breugel K Van, Fraaij ALA (2003) Experimental Study and Numerical Simulation of the Development of the Microstructure and Permeability of Cementitious Materials

41. Gurney L, Bentz D, Sato T, Weiss W (2012) Reducing set retardation in high-volume fly ash mixtures with the use of limestone. Transp Res Rec. https://doi.org/10.3141/2290-18

42. Niewiadomski P, Hoła J, Ćwirzeń A (2018) Study on properties of self-compacting concrete modified with nanoparticles. Arch Civ Mech Eng 18:877-886. https://doi.org/10.1016/j.acme.2018.01. 006

43. Dinakar P, Kartik Reddy M, Sharma M (2013) Behaviour of self compacting concrete using Portland pozzolana cement with different levels of fly ash. Mater Des 46:609-616. https://doi.org/ 10.1016/j.matdes.2012.11.015

44. García Calvo JL, Pérez G, Carballosa P, Erkizia E, Gaitero JJ, Guerrero $A$ (2017) Development of ultra-high performance concretes with self-healing micro/nano-additions. Constr Build Mater 138:306-315. https://doi.org/10.1016/j.conbuildmat.2017.02. 015

45. Palla R, Karade SR, Mishra G, Sharma U, Singh LP (2017) High strength sustainable concrete using silica nanoparticles. Constr Build Mater 138:285-295. https://doi.org/10.1016/j.conbu ildmat.2017.01.129

46. Ganesh P, Murthy AR, Kumar SS, Reheman MMS, lyer NR (2016) Effect of nanosilica on durability and mechanical properties of high-strength concrete. Mag Concr Res 68:229-236. https://doi. org/10.1680/jmacr.14.00338

47. Bastami M, Baghbadrani M, Aslani F (2014) Performance of nano-Silica modified high strength concrete at elevated temperatures. Constr Build Mater 68:402-408. https://doi.org/10. 1016/j.conbuildmat.2014.06.026

48. Sato T (2006) The effect of nano-sized $\mathrm{CaCO} 3$ addition on the hydration of OPC containing high volumes of ground granulated blast-furnace slag. https://doi.org/10.1617/2351580028. 077

49. Yu R, Spiesz P, Brouwers HJH (2014) Effect of nano-silica on the hydration and microstructure development of Ultra-High Performance Concrete (UHPC) with a low binder amount. Constr Build Mater 65:140-150. https://doi.org/10.1016/j.conbuildmat.2014. 04.063

50. Ai-khalaf MN, Yousift HA (1984) Use of rice h u s k ash in concrete. Int J Cem Compos Light Concr 6:241-248

51. Madani H, Bagheri A, Parhizkar T, Raisghasemi A (2014) Chloride penetration and electrical resistivity of concretes containing nanosilica hydrosols with different specific surface areas. Cem Concr Compos 53:18-24. https://doi.org/10.1016/j.cemco ncomp.2014.06.006

52. Douba A, Genedy M, Matteo EN, Kandil UF, Stormont J, Reda Taha MM (2017) The significance of nanoparticles on bond strength of polymer concrete to steel. Int J Adhes Adhes 74:7785. https://doi.org/10.1016/j.ijadhadh.2017.01.001

53. Naik TR, Singh SS, Hossain MM (1994) Abrasion resistance of concrete as influenced by inclusion of fly ash. Cem Concr Res 24:303-312. https://doi.org/10.1016/0008-8846(94)90056-6

54. Atiş CD (2002) High volume fly ash abrasion resistant concrete. J Mater Civ Eng 14:274-277. https://doi.org/10.1061/(asce)08991561(2002)14:3(274)

55. Sobolev K, Flores I, Hermosillo R, Torres-Martínez LM (2008) Nanomaterials and nanotechnology for high-performance cement composites. In: American Concrete Institute, ACI Special Publication pp 93-120
56. Zapata LE, Portela G, Suárez OM, Carrasquillo O (2013) Rheological performance and compressive strength of superplasticized cementitious mixtures with micro/nano-SiO2 additions. Constr Build Mater 41:708-716. https://doi.org/10.1016/j.conbuildmat. 2012.12.025

57. Singh LP, Goel A, Bhattachharyya SK, Ahalawat S, Sharma U, Mishra G (2015) Effect of morphology and dispersibility of silica nanoparticles on the mechanical behaviour of cement mortar. Int J Concr Struct Mater 9:207-217. https://doi.org/10.1007/ s40069-015-0099-2

58. Kawashima S, Seo JWT, Corr D, Hersam MC, Shah SP (2014) Dispersion of $\mathrm{CaCO} 3$ nanoparticles by sonication and surfactant treatment for application in fly ash-cement systems. Mater Struct Constr 47:1011-1023. https://doi.org/10.1617/ s11527-013-0110-9

59. Du H, Du S, Liu X (2014) Durability performances of concrete with nano-silica. Constr Build Mater 73:705-712. https://doi.org/ 10.1016/j.conbuildmat.2014.10.014

60. Shih JY, Chang TP, Hsiao TC (2006) Effect of nanosilica on characterization of Portland cement composite. Mater Sci Eng A 424:266-274. https://doi.org/10.1016/j.msea.2006.03.010

61. Land G, Stephan D (2015) Controlling cement hydration with nanoparticles. Cem Concr Compos 57:64-67. https://doi.org/10. 1016/j.cemconcomp.2014.12.003

62. Barkoula NM, loannou C, Aggelis DG, Matikas TE (2016) Optimization of nano-silica's addition in cement mortars and assessment of the failure process using acoustic emission monitoring. Constr Build Mater 125:546-552. https://doi.org/10.1016/j. conbuildmat.2016.08.055

63. Haruehansapong S, Pulngern T, Chucheepsakul S (2014) Effect of the particle size of nanosilica on the compressive strength and the optimum replacement content of cement mortar containing nano-SiO2. Constr Build Mater 50:471-477. https://doi.org/10. 1016/j.conbuildmat.2013.10.002

64. Ji T (2005) Preliminary study on the water permeability and microstructure of concrete incorporating nano-SiO2. Cem Concr Res 35:1943-1947. https://doi.org/10.1016/j.cemconres.2005. 07.004

65. Björnström J, Martinelli A, Matic A, Börjesson L, Panas I (2004) Accelerating effects of colloidal nano-silica for beneficial calcium-silicate-hydrate formation in cement. Chem Phys Lett 392:242-248. https://doi.org/10.1016/j.cplett.2004.05.071

66. Hou P, Kawashima S, Kong D, Corr DJ, Qian J, Shah SP (2013) Modification effects of colloidal nanoSiO2 on cement hydration and its gel property. Compos Part B Eng 45:440-448. https://doi. org/10.1016/j.compositesb.2012.05.056

67. Najigivi A, Khaloo A, Iraji Zad A, Abdul Rashid S (2013) Investigating the effects of using different types of $\mathrm{SiO} 2$ nanoparticles on the mechanical properties of binary blended concrete. Compos Part B Eng 54:52-58. https://doi.org/10.1016/j.compositesb. 2013.04.035

68. Yousefi A, Allahverdi A, Hejazi P (2013) Effective dispersion of nano-TiO2 powder for enhancement of photocatalytic properties in cement mixes. Constr Build Mater 41:224-230. https:// doi.org/10.1016/j.conbuildmat.2012.11.057

69. Bałdyga J, Orciuch W, Makowski $Ł$, Malik K, Özcan-Taşkin G, Eagles W, Padron G (2008) Dispersion of nanoparticle clusters in a rotor-stator mixer. Ind Eng Chem Res 47:3652-3663. https:// doi.org/10.1021/ie070899u

Publisher's Note Springer Nature remains neutral with regard to jurisdictional claims in published maps and institutional affiliations. 